\title{
Real Collars as Alternative Incentives for Subsidizing Energy Facilities
}

\section{Roger Adkins*}

Bradford University School of Management

\section{Dean Paxson**}

Alliance Manchester Business School

JEL Classifications : C72, D81, G31, H25, Q48

Keywords: Economic Incentives, Collar Options, Price Floors and Ceilings, Subsidized Energy Facilities

Acknowledgements: We thank Alcino Azevedo, Luiz Brandão, Huawan Li, Paulo Pereira, Artur Rodrigues, Chaoyan Wu, and Carlos Zapata and Carlos Mejiá (the ROC- Boston 2017 discussants), and an anonymous referee for helpful comments on earlier versions.

*Bradford University School of Management, Emm Lane, Bradford BD9 4JL, UK.

r.adkins@bradford.ac.uk +44 (0)1274233466.

Honorary Research Fellow, Alliance Manchester Business School, Booth St West, Manchester, M15 6PB, UK

${ }^{* *}$ Alliance Manchester Business School, Booth St West, Manchester, M15 6PB, UK.

dean.paxson@mbs.ac.uk+44(0)1612756456. Corresponding author 


\title{
Real Collars as Alternative Incentives for Subsidizing Energy Facilities
}

\begin{abstract}
We suggest that real collars may be an acceptable incentive for encouraging development of low (or no) carbon energy generating facilities as an alternative for high feed-in-tariffs. Composed of pairs of put and call American perpetuity options, feasible collars perform a similar role as subsidies by raising the value of an energy generator. We provide novel analytical solutions for real collars and partial collars, plus floor and ceiling partial derivatives. The "gains/losses" of the energy generator as perceived parameter values change are compared to those of the government providing the collar, and floor or ceiling only, viewing the arrangement as a real option game between principal and agent. A volatility increase first increases, then decreases the "gains" of the generator.
\end{abstract}




\section{Introduction}

We present a collar option as a suitable policy device for a government (GOV) providing a subsidy for a private energy generator (GEN) by guaranteeing a floor in the face of adverse circumstances, and simultaneously capturing abnormally high returns when the circumstances are sufficiently favorable. The analysis of collars adopts a real option formulation because the guarantee on the downside and bonus compensation for the government on the upside are expressible as real options. Using an American perpetuity model, a minimum price guarantee (with a high ceiling) can create a value equivalent to a high feed-in-tariff which has often been used in the UK.

The National Audit Office (2016, 2017) states that the Hinkley Point C Arrangement (HPCA) involves a subsidy to the state supported EDF and CGN entities of a present value of some 30 billion pounds, as the difference between the feed-in-tariff (92.5 pounds per MWhr in 2012 prices) and the current UK electricity price as of March 2016. Possible benefits for the U.K. government in the HPCA are reductions in the feed-in-tariff for electricity if construction costs are below expected levels, and a payment to the GOV if eventually the project IRR exceeds specified levels. The National Audit Office (2017) does not investigate the incentives for the GEN to control construction costs, or to operate just short of the level that triggers an upside call option $^{1}$, or to reduce the project volatility by hedging or issuing electricity price risk sharing debt instruments. An alternative collar with a guaranteed electricity price at or below the current UK electricity price could provide equivalent value for the nuclear GEN².

There is a vast literature on subsidies used to promote certain types of energy facilities, which Couture and Gagnon (2009) separate into market independent (feed-in-tariffs) and market dependent categories. One market independent subsidy cited is the Spanish 2007 "variable premium" that involves a type of floor and cap, where the highest premium (over the market electricity price) is paid when the electricity price is low, and zero when the price exceeds a

\footnotetext{
${ }^{1}$ The Hinkley Point C agreement, expected to operate for 60 years, specifies that the GOV (on behalf of UK electricity customers) may recover some of the construction costs less than the expected amounts, and obtain a payment from the GEN if the IRR on the project turns out to be more than $11.4 \%$. The concessionaire is owned by Électricité de France (EDF) and China General Nuclear Power Group (CGN).

${ }^{2}$ A case study showing that the approximate value of the current FiT for HPCA might be replicated by a suitable floor and ceiling is available from the authors.
} 
ceiling (so the GEN receives all of the higher price, without a premium). González (2009) provides some detail on these premium collars, which were (€ cents/kWh) 25.4-34.4 for solar, 7.3-8.5 for small on-shore wind, and 15.4-16.6 for energy crops in 2007. Meira et al. (2008) illustrates how this system worked for wind power during 2006. Brandão and Saraiva (2008) and Shan et al. (2010) propose that government guarantees for infrastructure projects should involve a European collar. Fernandes et al. (2015) suggest a collar-type insurance for wind power in Brazil, where the generator has promised to supply power even during times where there is little wind. Except for European collars, these authors do not propose analytical solutions for these long-life collar arrangements.

There are some analytical studies for perpetual subsidies (Boomsma and Linnerud, 2015, Adkins and Paxson, 2015), and for perpetual floors/ceilings. Takashima et al. (2010) design a privatepublic partnership (PPP) deal involving government debt participation that incorporates a floor on the future maximum loss level where the investor has the right to sell back the project whenever adverse conditions emerge. Armada et al. (2012) make an analytical comparison of various subsidy policies including minimum revenue guarantees.

Several authors focus on the conflict between a principal GOV and agent concessionaire GEN implicit in contracts. Chevalier-Roignant et al. (2011) and Azevedo and Paxson (2014) survey many real option game problems between principal and agent. Scandizzo and Ventura (2010) focus on "calculating a baseline to organize a concession contract...to measure the balance of power between the public and the private party”.

Our contribution consists of analytical models for a post-investment (ACTIVE) collar, so the costs and benefits to the GEN and GOV can be clearly identified, initially and as the parameter values evolve over time. Also, it is easy to see what initial parameter values the GEN and GOV are likely to over (under) estimate or emphasize, and what basic incentives are evident for the two parties to a subsidized energy facility arrangement. The basic game theory applicable to a principal and an agent is that the incentives for the agent should be allied to the objectives of the principal, and that the principal monitors periodically the performance of the agent to see whether those objectives are being met.

This paper is organized in the following way. In the next section, we formulate the collar model analytically, along with floor only and ceiling only models. In section 3 , we show the analytical 
partial derivatives of the calls and puts with respect to changing the floor/ceiling, perhaps useful for both parties in negotiating a satisfactory arrangement. In section 4, further insights are gained from performing a numerical sensitivity analysis. Section 5 presents some of the more interesting aspects of "who wins, who loses, why" between the GEN and GOV as parameter values change. The versatility of the analytical representation is demonstrated in section 6 through an extension to partial collars. Section 7 is a conclusion.

\section{Fundamental Models}

For a firm in a monopolistic situation confronting a sole source of uncertainty due to output price $^{3}$ variability, and ignoring operating costs and taxes, the operation of an energy generator depends primarily (or solely) on the electricity price evolution, which is specified by the geometric Brownian motion process ${ }^{4}$ :

$$
\mathrm{d} P=\alpha P \mathrm{~d} t+\sigma P \mathrm{~d} W
$$

where $\alpha$ denotes the expected price risk-neutral drift, $\sigma$ the price volatility, and $\mathrm{d} W$ an increment of the standard Wiener process. Using contingent claims analysis, the option to operate the project $F(P)$ follows the risk-neutral valuation relationship:

$$
\frac{1}{2} \sigma^{2} P^{2} \frac{\partial^{2} F}{\partial P^{2}}+(r-\delta) P \frac{\partial F}{\partial P}-r F=0
$$

where $r>\alpha$ denotes the risk-free interest rate and $\delta=r-\alpha$ thee convenience yield or the rate of return shortfall. The generic solution to (2) is:

$$
F(P)=A_{1} P^{\beta_{1}}+A_{2} P^{\beta_{2}}
$$

where $A_{1}, A_{2}$ are to be determined generic constants for calls and puts, and $\beta_{1}, \beta_{2}$ are, respectively, the positive and negative roots of the fundamental equation, which are given by:

\footnotetext{
${ }^{3}$ This assumption is perhaps more valid for nuclear power, which operates at a constant baseload except for some planned (and also emergency) outages. This model can easily be altered to involve quantity (Q) uncertainty where $\mathrm{R}=\mathrm{P} * \mathrm{Q}$. However, our analysis assumes $\mathrm{Q}$ is ignored, but the original construction cost is expressed in terms of unit capacity for Q.

${ }^{4}$ Tests for whether gBm process is appropriate for UK monthly baseload electricity prices are available from the authors, some similar to those in Dockendorf and Paxson (2013).
} 


$$
\beta_{1}, \beta_{2}=\left(\frac{1}{2}-\frac{r-\delta}{\sigma^{2}}\right) \pm \sqrt{\left(\frac{1}{2}-\frac{r-\delta}{\sigma^{2}}\right)^{2}+\frac{2 r}{\sigma^{2}}}
$$

In (3), if $A_{2}=0$ then $F$ is a continuously increasing function of $P$ and represents an American perpetual call option, Samuelson (1965), while if $A_{1}=0$ then $\mathrm{F}$ is a decreasing function and represents a put option, Merton (1973) and Merton (1990).

\subsection{Real Collar Option for an ACTIVE Project}

A collar option is designed to confine the output price for an active project to a tailored range, by restricting its value to lie between a floor $P_{L}$ and a cap $P_{H}$. Whenever the price trajectory falls below the floor, the received output price is assigned the value $P_{L}$, and whenever it exceeds the cap, it is assigned the value $P_{H}$. By restricting the price to this range, the firm benefits from receiving a price that never falls below $P_{L}$ and obtains protection against adverse price movements, whilst at the same time, it is being forced never to receive a price exceeding $P_{H}$, and so sacrifices the upside potential. For an active project, the revenue accruing to the firm is given by $\pi_{C}(P)=\min \left\{\max \left\{P_{L}, P\right\}, P_{H}\right\} \times Q$ (we assume $\mathrm{Q}=1$ ) and its value $V_{C}$ is described by the risk-neutral valuation relationship:

$$
\frac{1}{2} \sigma^{2} P^{2} \frac{\partial^{2} V_{C}}{\partial P^{2}}+(r-\delta) P \frac{\partial V_{C}}{\partial P}-r V_{C}+\pi_{C}(P)=0
$$

The valuation of a with-collar active project is conceived over three mutually exclusive exhaustive regimes, I, II and III, specified on the $P$ line, each with its own distinct valuation function. Regimes I, II and III are defined by $P \leq P_{L}, P_{L}<P<P_{H}$ and $P_{H} \leq P$, respectively. Over Regime I, the firm is granted a more attractive fixed price $P_{L}$ compared with the variable price $P$, but also possesses a call-style option to switch to the more favorable Regime II as soon as $P$ exceeds $P_{L}$. This switch option increases in value with $P$ and has the generic form $A P^{\beta_{1}}$, where $A$ denotes a to be determined generic coefficient. Over Regime III, the firm is not only 
obliged to accept the less attractive fixed price $P_{H}$ instead of $P$ but also has to sell a put-style option to switch to the less favorable Regime II as soon as $P$ falls below $P_{H}$. This switch option decreases in value with $P$ and has the generic form $A P^{\beta_{2}}$. Over Regime II, the firm receives the variable price $P$, possesses a put-style option to switch to the more favorable Regime I as soon as $P$ falls to $P_{L}$, but sells a call-style option to switch to the less favorable Regime III as soon as $P$ attains $P_{H}$. The various switch options are displayed in Table 1 , where $A$ denotes a generic coefficient.

Table 1: The Various Switch Options

$\begin{array}{llcl}\text { From - To } & \text { Option Type } & \text { Value } & \text { Sign of } A \\ \text { I - II } & \text { Call } & A P^{\beta_{1}} & + \\ \text { II - I } & \text { Put } & A P^{\beta_{2}} & + \\ \text { II - III } & \text { Call } & A P^{\beta_{1}} & - \\ \text { III - II } & \text { Put } & A P^{\beta_{2}} & -\end{array}$

If the subscript $C$ denotes the with-collar arrangement, then after paying the investment cost, the valuation function for the firm owning the ACTIVE project is:

$$
V_{C}(P)= \begin{cases}\frac{P_{L}}{r}+A_{C 11} P^{\beta_{1}} & \text { for } P \leq P_{L} \\ \frac{P}{\delta}+A_{C 21} P^{\beta_{1}}+A_{C 22} P^{\beta_{2}} & \text { for } P_{L}<P<P_{H} \\ \frac{P_{H}}{r}+A_{C 32} P^{\beta_{2}} & \text { for } P_{H} \leq P .\end{cases}
$$

In (6), the first numerical subscript for a coefficient denotes the regime $\{1=I, 2=I I, 3=I I I\}$, while the second denotes a call if 1 or a put if 2. The coefficients $A_{C 11}, A_{C 22}$ are expected to be positive because the firm owns the options and a switch is beneficial. In contrast, $A_{C 21}, A_{C 32}$ are 
expected to be negative because the firm is writing the options and is being penalized by the switch. The real collar is composed of a pair of both call and put options. The first pair facilitates switching back and forth between Regime I and II, which results in an advantage for the GEN, while the second pair facilitates switching back and forth between Regime II and III, which results in a disadvantage for the firm. The real collar design differs from the typical European collar, which only involves buying and selling two distinct options.

A switch in either direction between Regime I and II occurs when $P=P_{L}$. It is optimal provided the value-matching relationship:

$$
\frac{P_{L}}{r}+A_{C 11} P^{\beta_{1}}=\frac{P}{\delta}+A_{C 21} P^{\beta_{1}}+A_{C 22} P^{\beta_{2}}
$$

and its smooth-pasting condition ${ }^{5}$ expressed as:

$$
\beta_{1} A_{C 11} P^{\beta_{1}}=\frac{P}{\delta}+\beta_{1} A_{C 21} P^{\beta_{1}}+\beta_{2} A_{C 22} P^{\beta_{2}}
$$

both hold when evaluated at $P=P_{L}$. Similarly, a switch in either direction between Regime II and III occurs when $P=P_{H}$. It is optimal provided the value-matching relationship:

$$
\frac{P}{\delta}+A_{C 21} P^{\beta_{1}}+A_{C 22} P^{\beta_{2}}=\frac{P_{H}}{r}+A_{C 32} P^{\beta_{2}}
$$

and its smooth-pasting condition expressed as:

$$
\frac{P}{\delta}+\beta_{1} A_{C 21} P^{\beta_{1}}+\beta_{2} A_{C 22} P^{\beta_{2}}=\beta_{2} A_{C 32} P^{\beta_{2}}
$$

both hold when evaluated at $P=P_{H}$. A novel expression for the option coefficients is:

\footnotetext{
${ }^{5}$ Obtained through multiplying both sides of the first derivative by P.
} 


$$
\begin{aligned}
& A_{C 11}=\left[\frac{P_{H}}{P_{H}^{\beta_{1}}}-\frac{P_{L}}{P_{L}^{\beta_{1}}}\right] \times \frac{\left(r \beta_{2}-r-\delta \beta_{2}\right)}{\left(\beta_{1}-\beta_{2}\right) r \delta}>0, A_{C 21}=\frac{P_{H}\left(r \beta_{2}-r-\delta \beta_{2}\right)}{P_{H}^{\beta_{1}}\left(\beta_{1}-\beta_{2}\right) r \delta}<0, \\
& A_{C 22}=\frac{-P_{L}\left(r \beta_{1}-r-\delta \beta_{1}\right)}{P_{L}^{\beta_{2}}\left(\beta_{1}-\beta_{2}\right) r \delta}>0, A_{C 32}=\left[\frac{P_{H}}{P_{H}^{\beta_{2}}}-\frac{P_{L}}{P_{L}^{\beta_{2}}}\right] \times \frac{\left(r \beta_{1}-r-\delta \beta_{1}\right)}{\left(\beta_{1}-\beta_{2}\right) r \delta}<0 .
\end{aligned}
$$

The signs of the four option coefficients comply with expectations. Other findings can also be derived. The coefficient $A_{C 22}$ for the option to switch from Regime II to I, which depends on only $P_{L}$ and not on $P_{H}$, increases in size with $P_{L}$. This switch option becomes more valuable for the firm as the floor level increases. Similarly, the coefficient $A_{C 21}$ for the option to switch from Regime II to III, which depends on only $P_{H}$ and not on $P_{L}$, decreases in magnitude with $P_{H}$. This switch option becomes less valuable for the government as the cap level increases. The coefficients $A_{C 11}$ and $A_{C 32}$ for the switch option from Regime I to II and from Regime III to II, respectively, depend on both $P_{L}$ and $P_{H}$.

\subsection{Floor and Cap Options}

The analogous results for the floor only and the cap (ceiling) only are shown below.

\section{Price Floor Model}

We use the additional subscript $f$ to indicate a model with only a floor. From (6) the active project valuation function becomes:

$$
V_{C f}(P)= \begin{cases}\frac{P_{L}}{r}+A_{C f 11} P^{\beta_{1}} & \text { for } P \leq P_{L} \\ \frac{P}{\delta}+A_{C f 22} P^{\beta_{2}} & \text { for } P_{L}<P,\end{cases}
$$

with:

$$
A_{C f 11}=\frac{-P_{L}\left(r \beta_{2}-r-\delta \beta_{2}\right)}{P_{L}^{\beta_{1}}\left(\beta_{1}-\beta_{2}\right) r \delta} \geq 0, A_{C f 22}=\frac{-P_{L}\left(r \beta_{1}-r-\delta \beta_{1}\right)}{P_{L}^{\beta_{2}}\left(\beta_{1}-\beta_{2}\right) r \delta} \geq 0 .
$$

A high floor is favorable for the firm, and so represents a government granted subsidy, Armada et al. (2012). 


\section{Price Cap Model}

We use the additional subscript $c$ to indicate a model with only a cap. From (6) the active project valuation function becomes:

$$
V_{C c}(P)=\left\{\begin{array}{lc}
\frac{P}{\delta}+A_{C c 21} P^{\beta_{1}} & \text { for } P<P_{H} \\
\frac{P_{H}}{r}+A_{C c 32} P^{\beta_{2}} & \text { for } P_{H} \leq P,
\end{array}\right.
$$

with:

$$
A_{C c 21}=\frac{P_{H}}{P_{H}^{\beta_{1}}} \frac{\left(r \beta_{2}-r-\delta \beta_{2}\right)}{\left(\beta_{1}-\beta_{2}\right) r \delta} \leq 0, \quad A_{C c 32}=\frac{P_{H}}{P_{H}^{\beta_{2}}} \frac{\left(r \beta_{1}-r-\delta \beta_{1}\right)}{\left(\beta_{1}-\beta_{2}\right) r \delta} \leq 0 .
$$

A ceiling is less desirable for the GEN than an operation without a cap, and consequently it is imposed by, for example, a government intent on offering a subsidy but shielding electricity customers against escalating prices.

\section{Collar and Floor and Ceiling Partial Derivatives}

Calculating the partial derivatives of the option coefficients with respect to changes in the floor or ceiling is novel, and perhaps enables each contracting party to view clearly the impact of different floor and/or ceiling levels on the real collar arrangement. The more traditional deltas (partial derivatives of the option coefficients and value of the floor or ceiling), and gammas (second derivative of the option coefficients and value of the floor or ceiling) are used to show that indeed the original ODE is solved, see Table 2.

The first derivatives of the ACTIVE option coefficients with respect to changes in $\mathrm{P}$ are as follows:

$$
\Delta V_{C}(P)=\left\{\begin{array}{lc}
\beta_{1} A_{C 11} P^{\beta_{1}-1} & \text { for } P \leq P_{L} \\
\frac{1}{\delta}+\beta_{1} A_{C 21} P^{\beta_{1}-1}+\beta_{2} A_{C 22} P^{\beta_{2}-1} & \text { for } P_{L}<P<P_{H} \\
\beta_{2} A_{C 32} P^{\beta_{2}-1} & \text { for } P_{H} \leq P .
\end{array}\right.
$$


The first derivatives of the ACTIVE option coefficients with respect to changes in $\mathrm{P}_{\mathrm{L}}$ are:

$$
\begin{aligned}
& A_{C 11}=\left[-\left(1-\beta_{1}\right) P_{L}^{-\beta_{1}}\right] \times \frac{\left(r \beta_{2}-r-\delta \beta_{2}\right)}{\left(\beta_{1}-\beta_{2}\right) r \delta}, \\
& A_{C 22}=\left[-\left(1-\beta_{2}\right) P_{L}^{-\beta_{2}}\right] \times \frac{\left(r \beta_{1}-r-\delta \beta_{1}\right)}{\left(\beta_{1}-\beta_{2}\right) r \delta}, \\
& A_{C 32}=\left[-\left(1-\beta_{2}\right) P_{L}^{-\beta_{2}}\right] \times \frac{\left(r \beta_{1}-r-\delta \beta_{1}\right)}{\left(\beta_{1}-\beta_{2}\right) r \delta} .
\end{aligned}
$$

The first derivatives of the ACTIVE option coefficients with respect to changes in $\mathrm{P}_{\mathrm{H}}$ are:

$$
\begin{aligned}
& A_{C 11}=\left[\left(1-\beta_{1}\right) P_{H}^{-\beta_{1}}\right] \times \frac{\left(r \beta_{2}-r-\delta \beta_{2}\right)}{\left(\beta_{1}-\beta_{2}\right) r \delta}, \\
& A_{C 21}=\left[\left(1-\beta_{1}\right) P_{H}^{-\beta_{1}}\right] \times \frac{\left(r \beta_{1}-r-\delta \beta_{1}\right)}{\left(\beta_{1}-\beta_{2}\right) r \delta}, \\
& A_{C 32}=\left[\left(1-\beta_{2}\right) P_{H}^{-\beta_{2}}\right] \times \frac{\left(r \beta_{1}-r-\delta \beta_{1}\right)}{\left(\beta_{1}-\beta_{2}\right) r \delta} .
\end{aligned}
$$

One reason for calculating the collar, and floor and ceiling “deltas”, is to provide an analytical framework for viewing the price exposure of a generator with a collar, compared to without a collar, and for displaying the significance of a proposed floor or ceiling on the value of option elements in any GOV and GEN arrangement.

\section{Numerical Illustrations}

Although the analytical results reveal some interesting properties, further insights into model behavior are obtainable from numerical evaluations. The base case parameter values are $\mathrm{Q}=1$, $\sigma=25 \%, \mathrm{r}=4 \%$, and $\delta=4 \%$. The evaluated power parameters for these values are $\beta_{1}=1.7369$ and $\beta_{2}=-0.7369$ from (4). The basic spreadsheet is Table 2, with the base case parameter values, which show that the option coefficient signs are as expected and that the ODE (5) is solved using the calculated delta (16) and gamma. 
In Table 3 the evaluated switch option coefficients, $A_{C 11}, A_{C 21}, A_{C 22}, A_{C 32}$ are shown in Panels A$\mathrm{D}$, respectively, for various floor and cap levels. The floor levels are chosen to vary between a minimum $P_{L}=0$ and a maximum $P_{L}=4$, and the cap levels between a minimum $P_{H}=10$, and a maximum $P_{H}=\infty$. As expected, all the four coefficients adopt the correct sign, $A_{C 21}$ is independent of $P_{L}$ and $A_{C 22}$ of $P_{H}$, while $A_{C 11}, A_{C 32}$ depend on both. Further, $A_{C 11}$, the coefficient for the option to switch from Regime I to II, decreases with $P_{L}$ but increases with $P_{H}$ , since for any feasible Regime I price level, the switch option is more valuable for lower $P_{L}$ levels because of the time value of money and that the price level is closer to $P_{L}$, and for higher $P_{H}$ levels because less is being sacrificed. Similarly, $A_{C 32}$, the negative coefficient for the option to switch from Regime III to II increases in magnitude with $P_{H}$ because of the time value of money and decreases with $P_{L}$ because less is being sacrificed. Finally, $A_{C 21}$, the negative coefficient for the option to switch from Regime II to III decreases in magnitude with $P_{H}$ because less is being sacrificed at higher $P_{H}$ levels, while $A_{C 22}$, the coefficient for the option to switch from Regime II to I increases with $P_{L}$ because more is being gained for higher $P_{L}$ levels. Note that the coefficients for the price floor are also available from Table 3 in the rows where $P_{H}=\infty$, while those for the price cap model are available from the columns where $P_{L}=0$.

\section{***Tables 2 \& 3 about here ${ }^{* * *}$}

The cost of the subsidy can be neutralized and the collar made "costless" by suitably engineering its floor and cap levels. For the ACTIVE GEN, a “costless collar” might be obtained equating the written call and protective put $A_{C 21} P^{\beta_{1}}, A_{C 22} P^{\beta_{2}}$ for $P_{L}<P<P_{H}$. For instance, for base case parameter values when $\mathrm{P}=6, \mathrm{P}_{\mathrm{L}}=4, \mathrm{P}_{\mathrm{H}}=15.6,-A_{C 21} P^{\beta_{1}}=A_{C 22} P^{\beta_{2}}$. Some illustrative “costless" $P_{L}$ and $P_{H}$ pairs are presented in Table 4 . The pairs are inversely related, as expected, since for the collar to remain "costless", any increase in the floor and reduction in downside risk has to be compensated by an additional sacrifice of the upside potential.

***Table 4 about here*** 


\subsection{Changes in Price}

Figure 1 shows that the collar value VC (6) exceeds the PV, left hand terms of (6) when P is low, VC and VC PV are equal when $\mathrm{P}=6$, since the floor and ceiling are designed as costless collars at $\mathrm{P}=6$ and the other base case parameter values, $\mathrm{VC}<\mathrm{VC} \mathrm{PV}$ when $\mathrm{P}>6$ as the option coefficients $\mathrm{A}_{\mathrm{C} 21}$ and $\mathrm{A}_{\mathrm{C} 22}$ decrease as $\mathrm{P}$ approaches and then exceeds $\mathrm{P}_{\mathrm{H}}$.

*** Figure 1 about here $* * *$

\subsection{Changes in Volatility}

Figure 2 shows that the VC first slightly exceeds VC PV as price volatility increases from nearly zero, but then falls short of the VC PV as volatility increases beyond $25 \%$, which is the base case where $A_{C 21}=-A_{C 22}$, a costless collar. The GEN has an incentive to hedge against increased volatility, but should welcome volatility slightly lower than $25 \%$.

*** Figure 2 about here $* * *$

\subsection{Changes in Interest Rate}

Figure 3 shows that the VC collar is somewhat less valuable as the interest rate increases past the base case rate of $4 \%$. The held put option becomes less valuable at high interest rates, and the negative written call option value much more negative as $r>4 \%$.

*** Figure 3 about here $* * *$

\subsection{Changes in Yield}

Figure 4 shows that the PV is significantly affected by changes in the yield, since between the floor and ceiling cash flows are valued dividing by the yield. From a costless collar when $\delta=4 \%$, the written call option increases much more than the held put option decreases when $\delta$ falls, but the PV of P increases, so in theory the GEN should favor yield decreases. Perhaps the interpretation that $\delta$ represents the convenience yield derived from the term structure of electricity futures prices implies that $\delta$ is exogeneous, so the GEN observes rather than influences $\delta$. Alternatively, perhaps this figure shows one of the limitations of the basic model.

*** Figure 4 about here $* * *$ 


\section{Risk Sharing: Who Wins, Who Loses, Why?}

In the principal-agent problem (GOV-GEN) and risk-sharing aspects of collar and floor or ceiling only arrangements, who wins, and who loses, as parameter values change are likely to be the indicators for GEN versus GOV incentives after the initial transaction. Initially, it is assumed that the GEN pays the "fair value" of the facility arrangement to the GOV, and the construction cost has already been paid by the GOV. In the base case, we also assume that the GOV has offered the GEN a "costless" real collar arrangement, where the value of a call written by the GEN to the GOV on upside prices higher than the ceiling $\mathrm{P}_{\mathrm{H}}$ and a put written by the GOV to the GEN on downside prices lower than a floor $\mathrm{P}_{\mathrm{L}}$ are equal and initially $\mathrm{P}_{\mathrm{L}}<\mathrm{P}<\mathrm{P}_{\mathrm{H}}$. It is assumed that both the GEN and the GOV agree on the initial and subsequent perceived parameter values, which is perhaps a heroic assumption. Disagreements and different views would produce different results and interpretations ${ }^{6}$. The effect of changes in the parameter values are zero-sum games, where the GEN gain/loss is equal to the GOV loss/gain, so that the GEN plus GOV is zero. Generally, the figures below confirm the previous figures on sensitivity, but are stated in an alternative format.

We show here six examples of GEN versus GOV results, as parameter values change. In Figure 5, from an initial "costless" collar if $\mathrm{P}_{\mathrm{L}}=4$ and $\mathrm{P}_{\mathrm{H}}=15.6$ and $\mathrm{P}=6$, if $\mathrm{P}$ increases, the GEN gains and GOV loses relatively in a zero-sum game.

*** Figure 5 about here ${ }^{* * *}$

In Figure 6a, from an initial volatility of $25 \%$ when $\mathrm{P}=6$, if volatility increases, in a zero-sum game (where the benefits and costs change, but remain equal to each other with opposite signs) the GEN suffers from the negative call increasing more than the put, and GOV benefits. If volatility decreases from 25\%, GEN benefits from the negative call decreasing less than the put, but when the volatility is close to zero, neither is of any value, thereby reverting to a costless collar.

\footnotetext{
${ }^{6}$ If the floor and ceiling are based on observable monthly average electricity prices, conceivably an independent third party could verify the price barriers as specified in any legal arrangement. However, different views of expected future price volatilities and convenience yields over several years could lead to both parties simultaneously justifying gains or losses using these real option models, hardly a zero-sum game.
} 
These volatility (vega) patterns are dependent on the level of $\mathrm{P}$ relative to $\mathrm{P}_{\mathrm{L}}$ and $\mathrm{P}_{\mathrm{H}}$. When $\mathrm{P}=2$, given the basic collar arrangement, the GOV gains when $A_{C 11}$ falls as volatility decreases below $25 \%$ as shown in Figure 6b. The opposite occurs when $\mathrm{P}=18$, given the basic collar arrangement, the GOV gains when - $\mathrm{A}_{\mathrm{C} 32}$ falls as volatility increases above $25 \%$ as shown in Figure 6c. As in Figure 2 the GEN is typically hurt by high volatility, which is not intuitive.

*** Figures 6a, $6 b$ and $6 c$ about here ***

In Figure 7, GEN loses if the interest rate rises above 4\%, and the GOV gains, showing perhaps that in the current low interest rate environment, previous collar arrangements are not necessarily good for investors, unless they have issued fixed rate long term debt without mandatory redemptions. It is hard to imagine a GOV benefitting or losing from a change in interest rates, since the basic interest rate is an economic policy instrument, and most GOVs have a mix of short and long-term debt, including pension and medical expense obligations.

\section{*** Figure 7 about here ***}

In Figure 8, suppose that $\delta$ represents the convenience yield derived from electricity futures, so a low $\delta$ implies a nearly flat term structure of future prices. If current futures forecast future prices, that is hardly beneficial for the GEN who benefits from higher $\mathrm{P}$ especially when $\mathrm{P}_{\mathrm{L}}<\mathrm{P}<\mathrm{P}_{\mathrm{H}}$, even though the effect on increasing the $\mathrm{PV}$ of the price maybe beneficial for the GEN. The so-called asset yield, dividend, or convenience yield, or return "shortfall” is a difficult concept to interpret in most applications, illustrated in this case.

*** Figure 8 about here $* * *$

It is interesting to compare collar arrangements with different floors and ceilings, and with floor only or ceiling only arrangements. Figure 9 shows the risk sharing collar arrangements between GEN and GOV as a function of various levels of the floor. It is natural that the GEN benefits (and the GOV suffers) from higher floors, in a zero-sum game.

\section{*** Figures 9 and 10 about here ***}

Equally dramatic in a zero-sum game is the effect of changes in price volatility on risk sharing when there is only a floor, or alternatively only a ceiling. Figure 10 shows the risk allocation with a floor only as a function of P volatility, but with the GEN benefit increasing with volatility 
up to a certain point (about 45\%), when thereafter volatility increases result in a decline of the GEN benefit, in contrast to Figures 6a and 6b for a collar.

\section{$6 \quad$ Partial Collars}

We now consider an additional illustrative case to investigate whether the findings for the plain vanilla collar formulation concerning the nature of the option coefficients extend to more complicated collar designs. We increase the number of regimes and formulate the shared revenue for the outer regimes of the collar to depend on a proportion (less than 100\%) of the revenue under the floors and over the ceilings. Our findings for this extension demonstrate that an analytical solution is obtainable despite the increase in complexity. Some of the sensitivities to changes in parameter values are similar to the previous collar model, but some are surprising. The notation we use in this section are specific, except that $\beta_{1}$ and $\beta_{2}$ are specified by (4).

Shaoul et al. (2012) report that for a U.K. rail franchise agreement, investors are reimbursed for $50 \%$ of any revenue shortfall below $98 \%$ of forecast and $80 \%$ below $96 \%$, but suffer a claw-back of $50 \%$ of revenue exceeding $102 \%$, equivalent to partial puts and calls. The Hinkley Point C arrangement specifies that if the project IRR exceeds $11.4 \%$ in nominal terms, the gain is shared 30:70 between the GOV and the GEN, and 60:40 if the IRR exceeds 13.5\% in nominal terms and $11.5 \%$ in real terms.

We suppose there is a symmetrical arrangement with two downside risk sharing and two upside risk sharing arrangements. The actual price for an output is denoted by P. For the purpose of determining the price to be received by the GEN, the agreement with the government divides the price schedule into 5 distinct exhaustive regimes. The four junctions for neighboring regimes occur at $P=P_{L L}$, where $P_{L L}$ represents the lowest limit, at $P=P_{L}$ where $P_{L}$ is the lower limit, at $P=P_{H}$ where $P_{H}$ is the higher limit, and at $P=P_{H H}$ where $P_{H H}$ is the highest limit. Under Regime I with $P<P_{L L}$, the "price received" by the GEN is the actual price $P$ plus a proportion $1-w_{L L}$ of the shortfall below $P_{L L}$ and a proportion $1-w_{L}$ of the difference $\left(\mathrm{P}_{\mathrm{L}}-\mathrm{P}_{\mathrm{LL}}\right)$. Under Regime II with $P_{L L} \leq P<P_{L}$, the price received is $P$ plus a proportion $1-w_{L}$ of the shortfall from $P_{L}$, where $0 \leq w_{L L} \leq w_{L} \leq 1$. Under Regime III with $P_{L} \leq P<P_{H}$, the price received is $P$, 
and under Regime IV with $P_{H} \leq P<P_{H H}$, the price received is $P$ less a proportion $1-w_{H}$ of $\left(P_{H}-P\right)$. Under Regime $\mathrm{V}$ with $P \geq P_{H H}$, the price received is $P$ less a proportion $1-w_{H H}$ of $\left(\mathrm{P}-\mathrm{P}_{\mathrm{HH}}\right)$ and less a proportion $1-w_{H}$ of $\left(\mathrm{P}_{\mathrm{HH}}-\mathrm{P}_{\mathrm{H}}\right)$, where $0 \leq w_{H H}<w_{H} \leq 1$. In the absence of any fixed costs and taxation, the regime value is determined not only from the price schedule but also from the presence of any switch options.

For each regime, if there exist opportunities for switching to an higher or lower neighboring regime, then these are represented by options, a call-style option for upward switching and a putstyle option for downward switching, so both Regime II , III and IV are characterized by both call and put options, while Regime I by a call and Regime V by a put. Also, a switch producing a price advantage is represented by a positive option value coefficient, while that for a price disadvantage by a negative coefficient. The specification and associated price values for each of the five regimes are listed in Table 5.

Table 5 Regime Specification and Price Schedule

\begin{tabular}{|c|c|c|}
\hline Regime & Specification & Value \\
\hline I & $P<P_{L L}$ & $\begin{aligned} V_{I}(P)= & A_{11} P^{\beta_{1}} \\
& +\frac{w_{L L} P}{\delta}+\frac{\left(1-w_{L}\right) P_{L}}{r}+\frac{\left(w_{L}-w_{L L}\right) P_{L L}}{r}\end{aligned}$ \\
\hline II & $P_{L L} \leq P<P_{L}$ & $\begin{aligned} V_{I I}(P)= & A_{21} P^{\beta_{1}}+A_{22} P^{\beta_{2}} \\
& +\frac{w_{L} P}{\delta}+\frac{\left(1-w_{L}\right) P_{L}}{r}\end{aligned}$ \\
\hline III & $P_{L} \leq P<P_{H}$ & $\begin{aligned} V_{I I I}(P)= & A_{31} P^{\beta_{1}}+A_{32} P^{\beta_{2}} \\
& +\frac{P}{\delta}\end{aligned}$ \\
\hline IV & $P_{H} \leq P<P_{H H}$ & $\begin{aligned} V_{I V}(P)= & A_{41} P^{\beta_{1}}+A_{42} P^{\beta_{2}} \\
& +\frac{w_{H} P}{\delta}+\frac{\left(1-w_{H}\right) P_{H}}{r}\end{aligned}$ \\
\hline
\end{tabular}




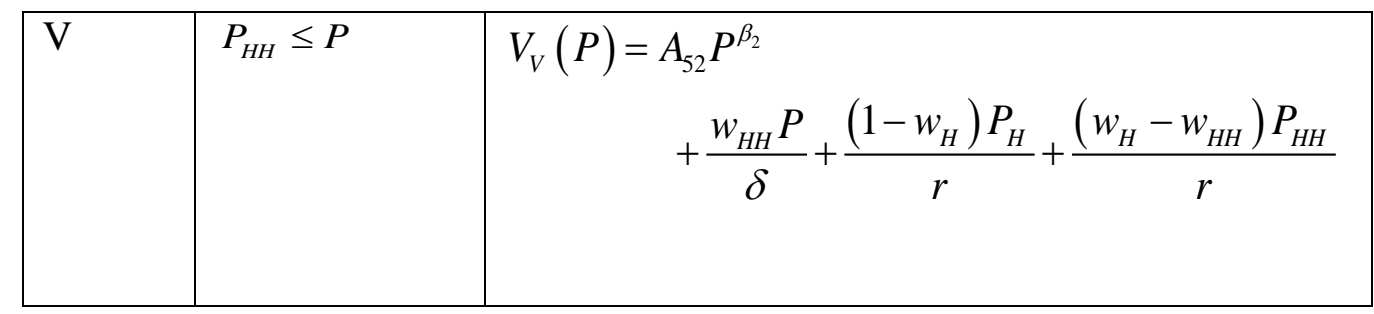

The eight unknown switch option coefficients, $A_{11}, A_{21}, A_{22}, A_{31}, A_{32}, A_{41}, A_{42}, A_{52}$, are determined from the value matching relationships and associated smooth pasting conditions. The value matching relationships, defined at each of the 4 junctions of neighboring regimes are:

$$
\begin{aligned}
& {\left.\left[V_{I I}(P)-V_{I}(P)\right]\right|_{P=P_{L L}}=0} \\
& {\left.\left[V_{I I I}(P)-V_{I I}(P)\right]\right|_{P=P_{L}}=0} \\
& {\left.\left[V_{I V}(P)-V_{I I I}(P)\right]\right|_{P=P_{H}}=0} \\
& {\left.\left[V_{V}(P)-V_{I V}(P)\right]\right|_{P=P_{H H}}=0}
\end{aligned}
$$

Equations (19)-(22) together with the 4 associated smooth pasting conditions are sufficient to solve for the unknowns. The resulting solutions together with their signs are presented in Table 6. The coefficients having a positive value indicate that the corresponding switch options are owned by the GEN and contribute to their value, whilst those having a negative sign are sold or written.

Table 6

Solutions and Conditions for the Switch Option Coefficients Partial Collar Model

\begin{tabular}{|l|l|}
\hline Coefficient Solution & Condition \\
\hline$A_{22}=\frac{\left(w_{L}-w_{L L}\right) P_{L L}\left(r \beta_{1}-r-\delta \beta_{1}\right)}{P_{L L}^{\beta_{2}}\left(\beta_{1}-\beta_{2}\right) r \delta}$ & $A_{22} \geq 0$ \\
\hline$A_{31}=-\frac{\left(1-w_{H}\right) P_{H}\left(r \beta_{2}-r-\beta_{2}\right)}{P_{H}^{\beta_{1}}\left(\beta_{1}-\beta_{2}\right) r \delta}$ & $A_{31} \leq 0$ \\
\hline$A_{21}=A_{31}+\frac{\left(1-w_{L}\right) P_{L}\left(r \beta_{2}-r-\delta \beta_{2}\right)}{P_{L}^{\beta_{1}}\left(\beta_{1}-\beta_{2}\right) r \delta}$ & $A_{21} \geq 0$ \\
\hline$A_{32}=A_{22}+\frac{\left(1-w_{L}\right) P_{H}\left(r \beta_{1}-r-\delta \beta_{1}\right)}{P_{H}^{\beta_{2}}\left(\beta_{1}-\beta_{2}\right) r \delta}$ & $A_{32} \geq 0$ \\
\hline
\end{tabular}




\begin{tabular}{|l|l|}
\hline$A_{11}=A_{21}+A_{22} \frac{P_{L L}^{\beta_{2}}}{P_{L L}^{\beta_{1}}}+\frac{\left(w_{L}-w_{L L}\right) P_{L L}(r-\delta)}{P_{L L}^{\beta_{1}} r \delta}$ & $A_{11} \geq 0$ \\
\hline$A_{41}=A_{31} \frac{P_{H}^{\beta_{1}}}{P_{H}^{\beta_{2}}}+A_{32}+\frac{\left(1-w_{H}\right) P_{H}(r-\delta)}{r \delta P_{H}^{\beta_{2}}}$ & \\
$A_{42}=A_{31} \frac{P_{H}^{\beta_{1}}}{P_{H}^{\beta_{2}}}+A_{32}+\frac{\left(1-w_{H}\right) P_{H}(r-\delta)}{r \delta P_{H}^{\beta_{2}}}-A_{41} \frac{P_{H}^{\beta_{1}}}{P_{H}^{\beta_{2}}}$ & $<0$ \\
$A_{52}=A_{41} \frac{P_{H H}^{\beta_{1}}}{P_{H H}^{\beta_{2}}}+A_{42}+\frac{\left(w_{H}-w_{H H}\right) P_{H H}(r-\delta)}{r \delta P_{H H}^{\beta_{2}}}$ & \\
\hline
\end{tabular}

The ACTIVE partial collars have somewhat different sensitivities to changes in $\mathrm{P}$ and $\mathrm{P}$ volatility than the previous "full" collars ${ }^{7}$. Partial collars with the parameter values the same as Table 2, except the layers, designed so the $\mathrm{VC}$ value is about the same $(\mathrm{VC}=138)$ as the basic result, are floors $3.5,4$, and ceilings $10,10.5$, and the risk sharing is .25 , .5 on the downside and $.5, .25$ on the upside. Figure 11 shows a decreasing sensitivity to increases in $\mathrm{P}$, which is intuitive compared to $100 \%$ risk sharing below the floor and above the ceiling. [While not exactly comparable due to the different ceiling, the value of a partial collar increases $96 \%$ and a full collar $76 \%$ as $\mathrm{P}$ goes from 6 to 18.]

The sensitivity of partial collar to changes in P volatility ("vegas”) are slightly different, with the VC partial collar also decreasing as volatility increases, as Figure 12 shows with $\mathrm{P}=6$ but with $\mathrm{P}=2$ and $\mathrm{P}=18$ below the figure.

***Figures 11 and 12 about here ***

How does the particular collar setting affect the exposure of a GEN to changes in prices, which is a critical risk consideration? Without a collar, the price exposure (delta) is of course simply $1 / \delta$, or the LHS term of (6). With a collar, the price exposure is the middle row of (16). When $\mathrm{P}=6$, Figure 13 shows that the ACTIVE project with a collar becomes less sensitive to changes in $\mathrm{P}$ as the floor increases, but the floor delta from the middle row of (17) becomes more important as the floor increases.

***Figure 13 about here $* * *$

\footnotetext{
${ }^{7}$ A spreadsheet for the partial collars is available from the authors.
} 


\section{Conclusion}

In a mainly analytical way, the properties of a plain vanilla collar, made up of a floor and cap, are investigated for an active asset using a real option formulation. The collar is composed of pairs of American perpetuity put and call options that confine a focal variable, such as revenue, price or volume, to a designated field specified by the floor and cap.

The role of the cap is to mitigate the cost to the government of guaranteeing a floor, and thereby inhibits the spread of any allegations of being over-generous. Governments can even create a "costless" collar by selecting a floor to induce investment and a cap that neutralizes the additional value it creates.

We provide novel analytical solutions for collars (11), floors only (13), ceilings only (15), floor (17) and ceiling deltas (18), and partial collars (Tables 5 and 6). In negotiating the original terms, it is critical for the GEN to focus on how the project value is sensitive to input changes, shown in Figures 1 to 4 . Another use of these analytical expressions is to identify clearly the gains and losses for a principal (GOV) and agent (GEN) participating in an energy generating facility as parameter values change, shown in Figures 5 to 9. Different real option games are envisioned, where changes in some of the parameter values after an initial deal result in a zerosum game. This basic framework may be useful in viewing the intended consequences of different appropriate arrangements, and in identifying incentives for the agent in operating a generating facility.

The primary numerical finding is that the GEN and GOV have contrasting "vegas" that is sensitivities to changes in perceived future price volatility, with generally the GEN hurt by high volatilities after the initial "fair" deal (Figures 2 and 6 a,b,c). Layered collars, and less than $100 \%$ risk sharing under the floors and over the ceilings expose the GEN less to changes in price (Figure 11) and price volatilities (Figure 12), which is intuitive. The precise exposure depends on the floor and ceiling levels relative to the current price (Figure 13), and on the degree of risk sharing (downside and upside proportions for different layers).

There are several implicit assumptions behind our analytical framework. (i) The arrangements are perpetual American call or put options, and a perpetual series of cash flows, viewed in continuous time. Real arrangements may not perpetual, so both the options and the cash flows 
would have to be reformatted as perpetuals less forward start options ${ }^{8}$, especially for shorterterm arrangements. This may not be a significant problem for 60 year arrangements when discount rates are high. (ii) Parameter values such as interest rates, yield, price volatility, price floors and ceilings are considered constant or deterministic. Relaxing some of these assumptions is an interesting extension. (iii) Sometimes arrangements specify that the concession termination is based on a specified achieved internal rate of return, or cumulative net present value, or accumulated net cash flows. We do not focus on negotiated exit prices or for GEN or GOV determined exit timing. (iv) GEN facilities and arrangements ignore GOV creditability issues and unexpected failures or physical disasters. GEN arrangements are envisioned as enforceable, without credit or default risk for either party, and investments are irrevocable, immediate, and terms cannot be re-negotiated over time. (v) The framework models are viewed in continuous time whereas prices, minimum and maximum revenue compensations and payments are likely to occur in discrete time, which would have to be specified (and verified) in any practical arrangement. (vi) We do not allow for operating costs that are not already deducted from the net price or net revenues, or for periodic maintenance requirements. (vii) The revenue stream ignores other possible real options such as project cancellation, downsizing, renegotiation, expansion and resale, dynamic pricing for times of usage, and extensions into other activities such as further arrangements with electricity customers, or retail activities for motorway operators. (viii) While the GEN arrangement cited herein concerns an electricity generating facility, other arrangements such as transportation, building and operating hospitals and educational establishments may not have clear objectives such as sharing revenue risks and benefits. Suitably designed optional elements may incorporate some of the same, or conceivably completely different objectives. Most of these issues present interesting aspects for future research, maybe starting with this basic framework.

\footnotetext{
${ }^{8}$ See Adkins et al. (2018) for a solution to this problem.
} 


\section{References}

Adkins, R., and D. Paxson. "Subsidies for Renewable Energy Facilities under Uncertainty" The Manchester School 84 (2016), 222-250, (online 2015).

Adkins, R., D. Paxson, P. Pereira, and A. Rodrigues. "Investment Decisions with Finite-lived Collars”, presented at the Real Options Conference Düsseldorf (2018).

Armada, M. R. J., P. J. Pereira, and A. Rodrigues. "Optimal Subsidies and Guarantees in Publicprivate Partnerships." The European Journal of Finance 18 (2012), 469-495.

Azevedo, A. and D. Paxson. “Developing Real Option Game Models” European Journal of Operational Research 237 (2014), 909-920.

Boomsma, T., and K. Linnerud. "Market and Policy Risk under Different Renewable Electricity Support Schemes", Energy 89 (2015), 435-448.

Brandão, L. and E. Saraiva. "The Option Value of Government Guarantees and Infrastructure Projects”, Construction Management and Economics 26 (2008), 1171-1180.

Chevalier-Roignant, B., C. Flath, A. Huchzermeier and L.Trigeorgis. "Strategic Investment under Uncertainty” European Journal of Operational Research 215 (2011), 639-650.

Couture, T., and Y. Gagnon. "An Analysis of Feed-in-Tariff Remuneration Models: Implications for Renewable Energy Investment", Energy Policy 38 (2009), 955-65.

Dockendorf, J, and D. Paxson. "Continuous Rainbow Options on Commodity Outputs: What is the Real Value of Switching Facilities?" The European Journal of Finance 19 (2013), 645-673.

Fernandes, G., L. Gomes, G. Vasconcelos, and L. Brandão. "Mitigating Wind Exposure with (Lower and Upper Bound) Collars-type Insurance", Real Options Conference, Athens 2015.

González, P. R. "Ten Years of Renewable Electricity Policies in Spain: An Analysis of Successive Feed-in-tariff Reforms", Energy Policy 36 (2008), 2917-2929.

Merton, R. C. "Theory of Rational Option Pricing." Bell Journal of Economics and Management Science 4 (1973), 141-183.

—. Continuous-Time Finance. Oxford: Blackwell Publishing (1990).

Miera, G.S., P.R. González and I. Vizcaíno. "Analyzing the Impact of Renewable Electricity Support Schemes on Power Prices: The Case of Wind Electricity in Spain" Energy Policy 36 (2008), 3345-3359.

National Audit Office. "Nuclear power in the U.K.", London: HM Stationary Office (2016).

National Audit Office. "Hinkley Point C.", London: HM Stationary Office (2017).

Samuelson, P. A. "Rational Theory of Warrant Pricing." Industrial Management Review 6 (1965), 
13-32.

Scandizzo, P.L. and M. Ventura. "Sharing Risk through Concession Contracts" European Journal of Operational Research 207 (2010), 363-370.

Shan, L., M.J. Garvin and R. Kumar. "Collar Options to Manage Revenue Risks in Real Toll Public-private Partnership Transportation Projects”, Construction Management and Economics 28 (2010), 1057-69.

Shaoul, J., A. Stafford, and P. Stapleton. "The Fantasy World of Private Finance for Transport via

Public Private Partnerships." OECD Publishing, Discussion Paper No. 2012-6 (2012).

Takashima, R., K. Yagi, and H. Takamori. "Government Guarantees and Risk Sharing in Publicprivate Partnerships." Review of Financial Economics 19 (2010), 78-83. 
Figure 1

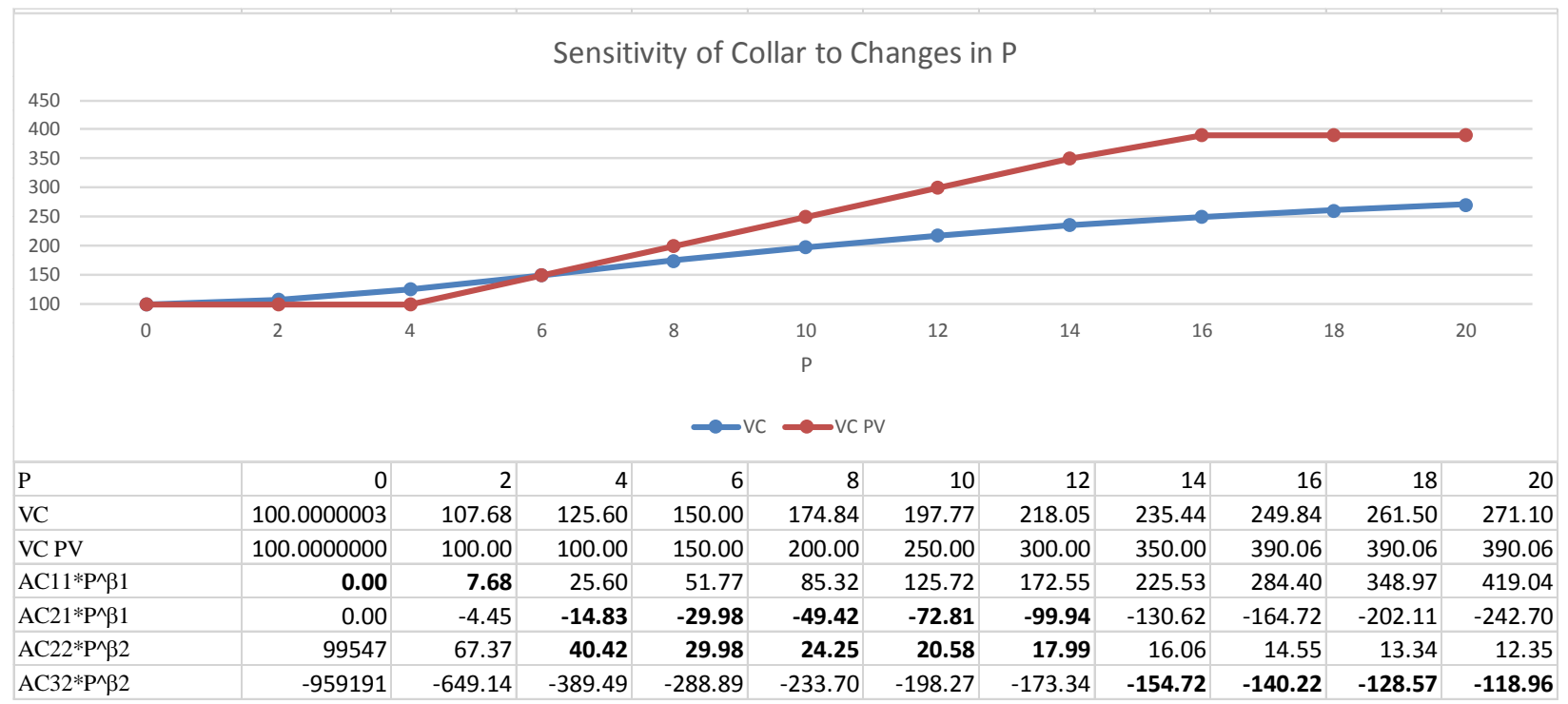

VC is from EQ 6, based on an initial arrangement of the base case in Table 2, except that $P_{L}=4$ and $P_{H}=15.6$ (a costless collar when $P=6$ ) where the option coefficient $A_{C 11}$ holds when $P<P_{L}$, and $A_{C 32}$ when $P>P_{H}$, otherwise $A_{C 21}$ and $A_{C 22}$, compared to the PV (6) without the option coefficients.

Figure 2

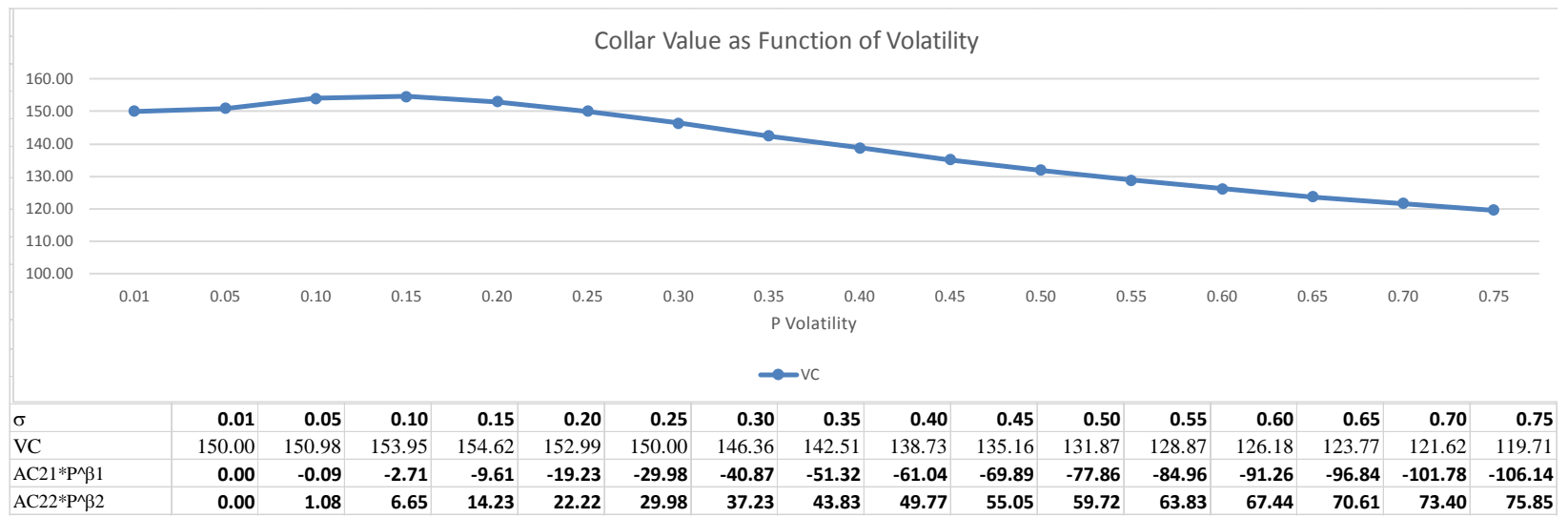

VC (6) is based on an initial arrangement of the base case in Table 2, except for varying volatility, if $P_{L}=4$ and $P_{H}=15.6$ (a costless collar when $P=6$ ). The option coefficients $-A_{C 21}=A_{C 22}$ only when $P=6$, but the negative call value increases at a faster rate than the put option coefficient as volatility increases past $25 \%$, so the collar arrangement is lower than the PV without the option coefficients at higher levels of volatility. 
Figure 3

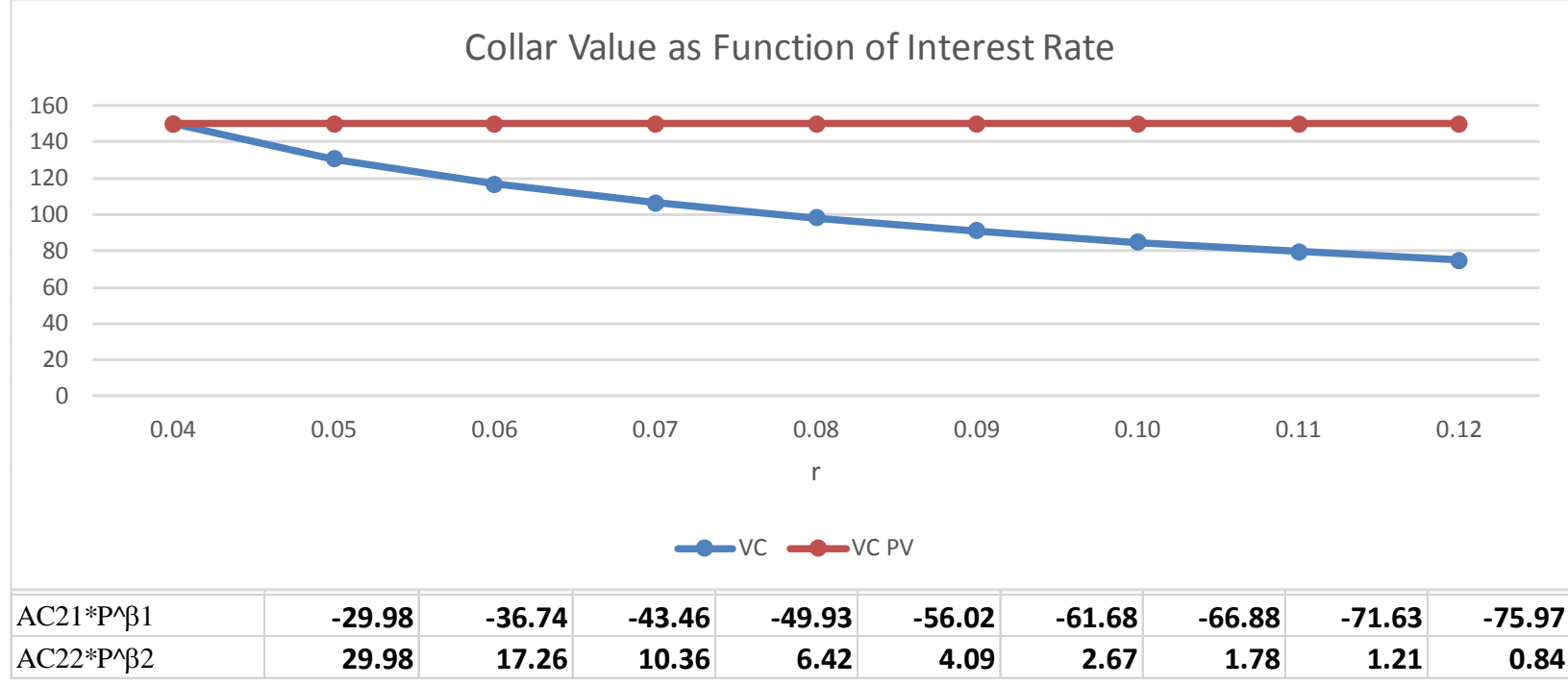

VC (6) is based on an initial arrangement of the base case in Table 2, except for varying the interest rate, when $P_{L}=4$ and $P_{H}=15.6$ (a costless collar) with $P=6$. The option coefficients $A_{C 21}$ and $A_{C 22}$ hold when $\mathrm{P}_{\mathrm{L}}<\mathrm{P}<\mathrm{P}_{\mathrm{H}}$. The collar arrangement is compared to the PV without the option coefficients. The PV is not affected by changes in the interest rate because the cash flows are uncertain, and so divided by the yield.

Figure 4

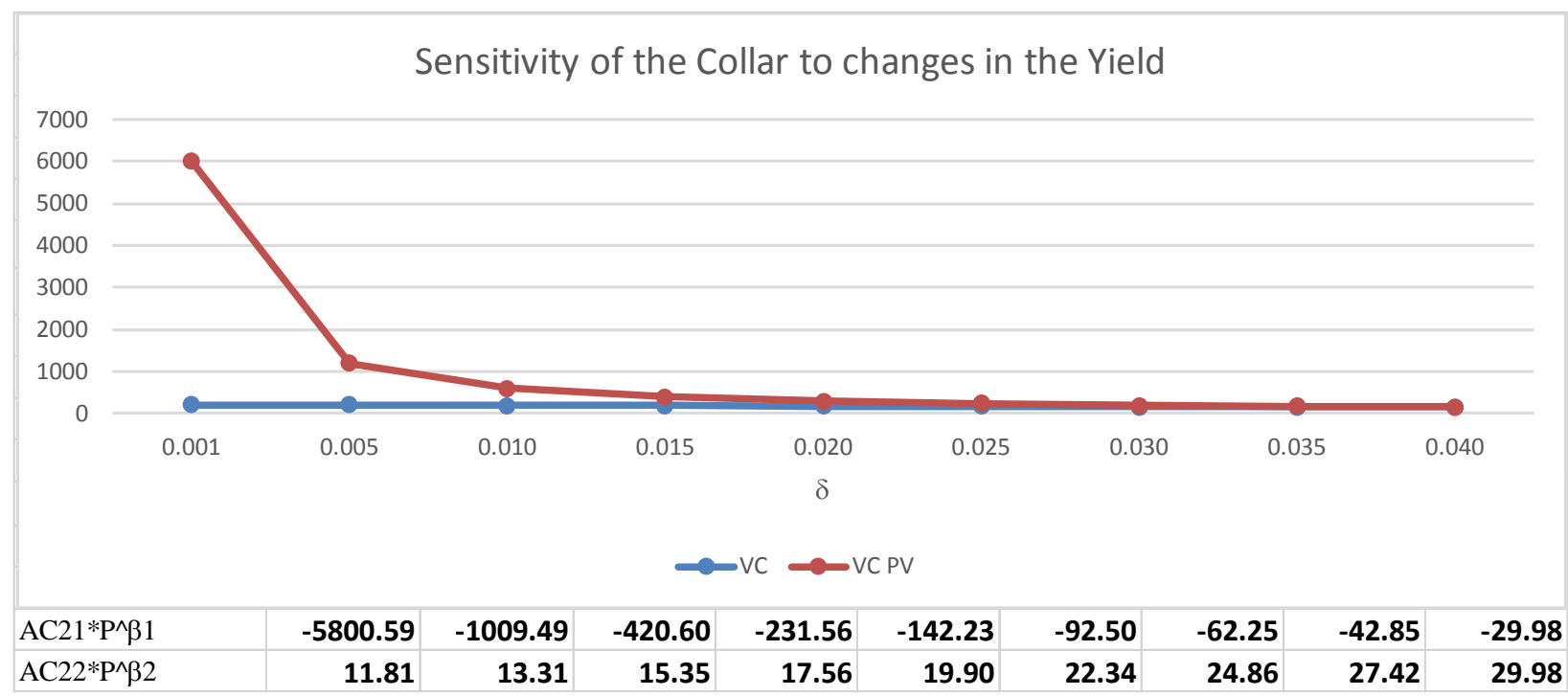

The VC (6) is based on an initial arrangement of the base case in Table 2, except for varying the yield, while $P_{L}=4$ and $P_{H}=15.6$ (a costless collar) with $P=6$. The option coefficients $A_{c 21}$ and $A_{c 22}$ hold when $\mathrm{P}_{\mathrm{L}}<\mathrm{P}<\mathrm{P}_{\mathrm{H}}$. The collar arrangement is compared to the $\mathrm{PV}$ without the option coefficients. 
Figure 5

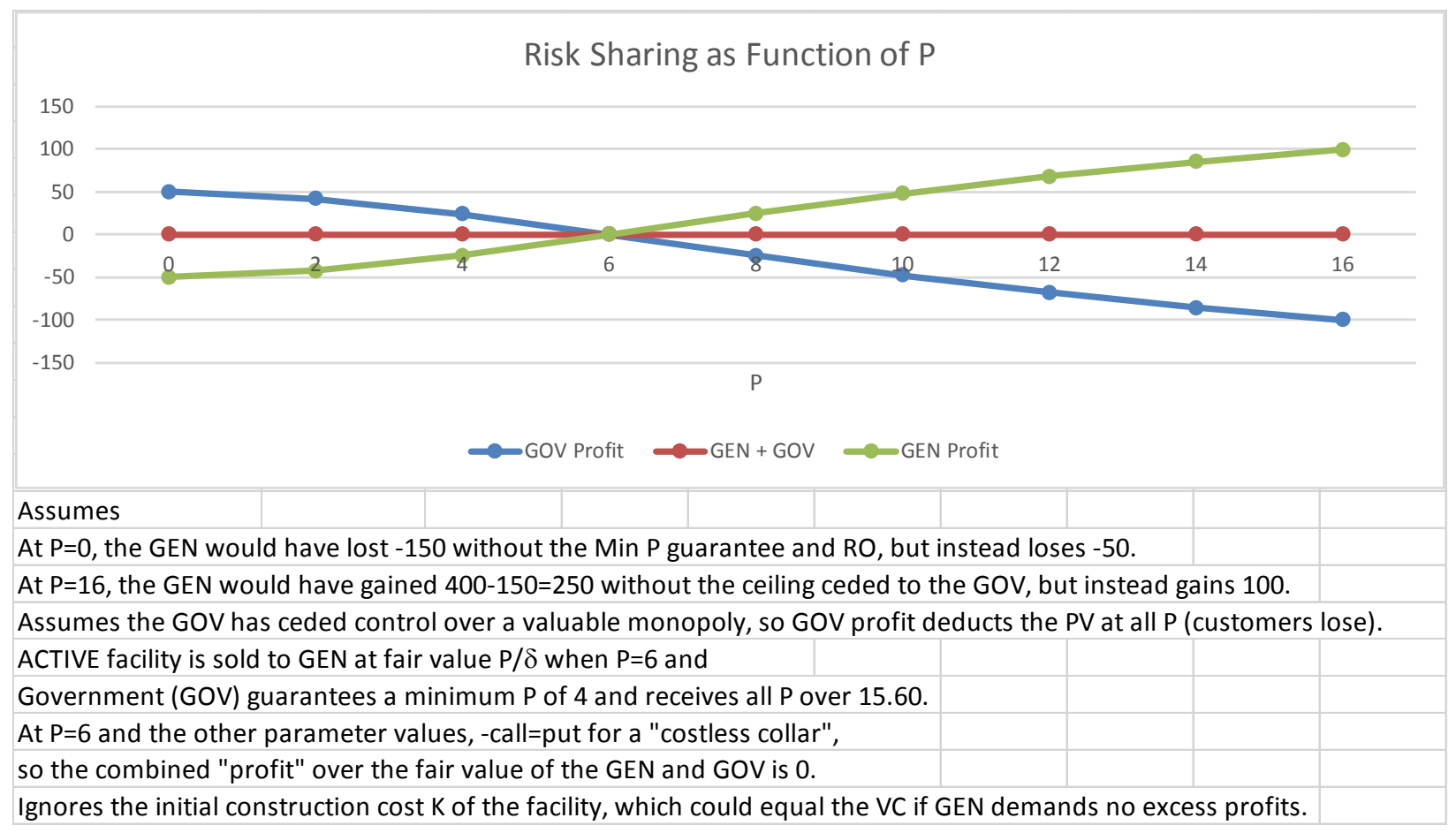

Figure 6a

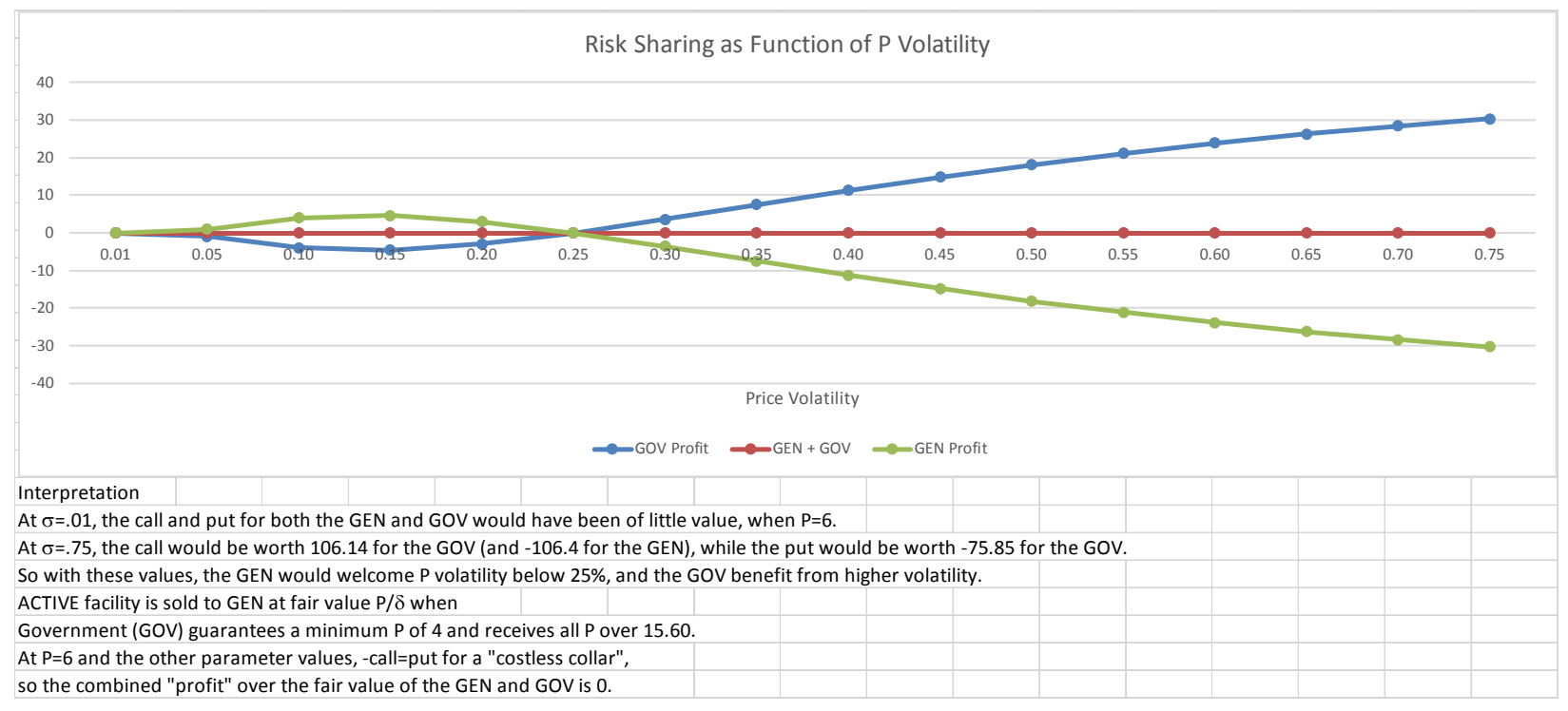




\section{Figure $6 b$}

\section{Volatility Effect on Risk Sharing $\left(\mathrm{Ac}_{11}\right)$ when $\mathrm{P}=2$}

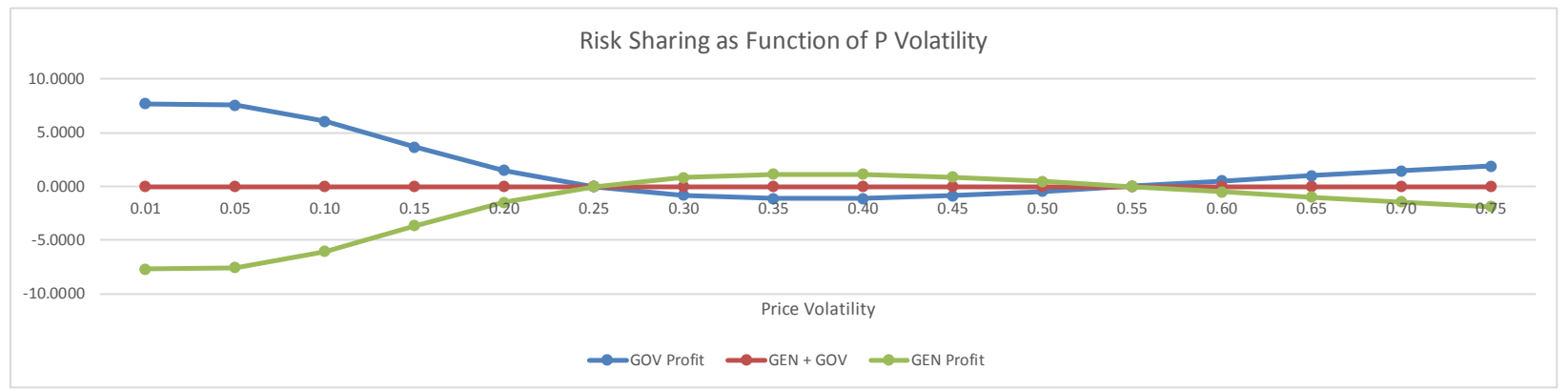

Figure 6c

Volatility Effect on Risk Sharing $\left(\mathrm{A}_{\mathrm{c} 32}\right)$ when $\mathrm{P}=18$

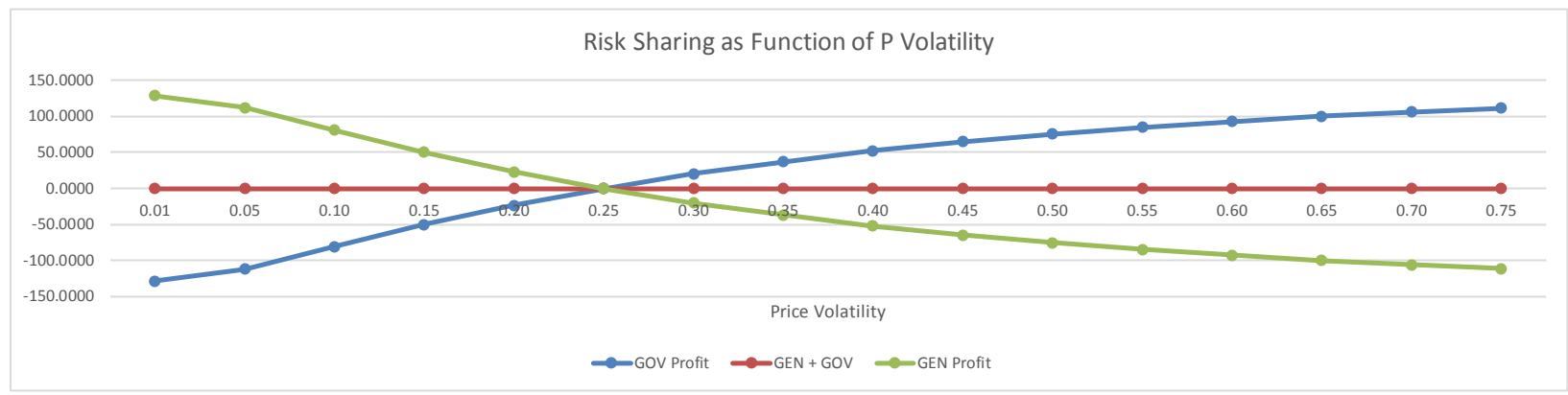


Figure 7

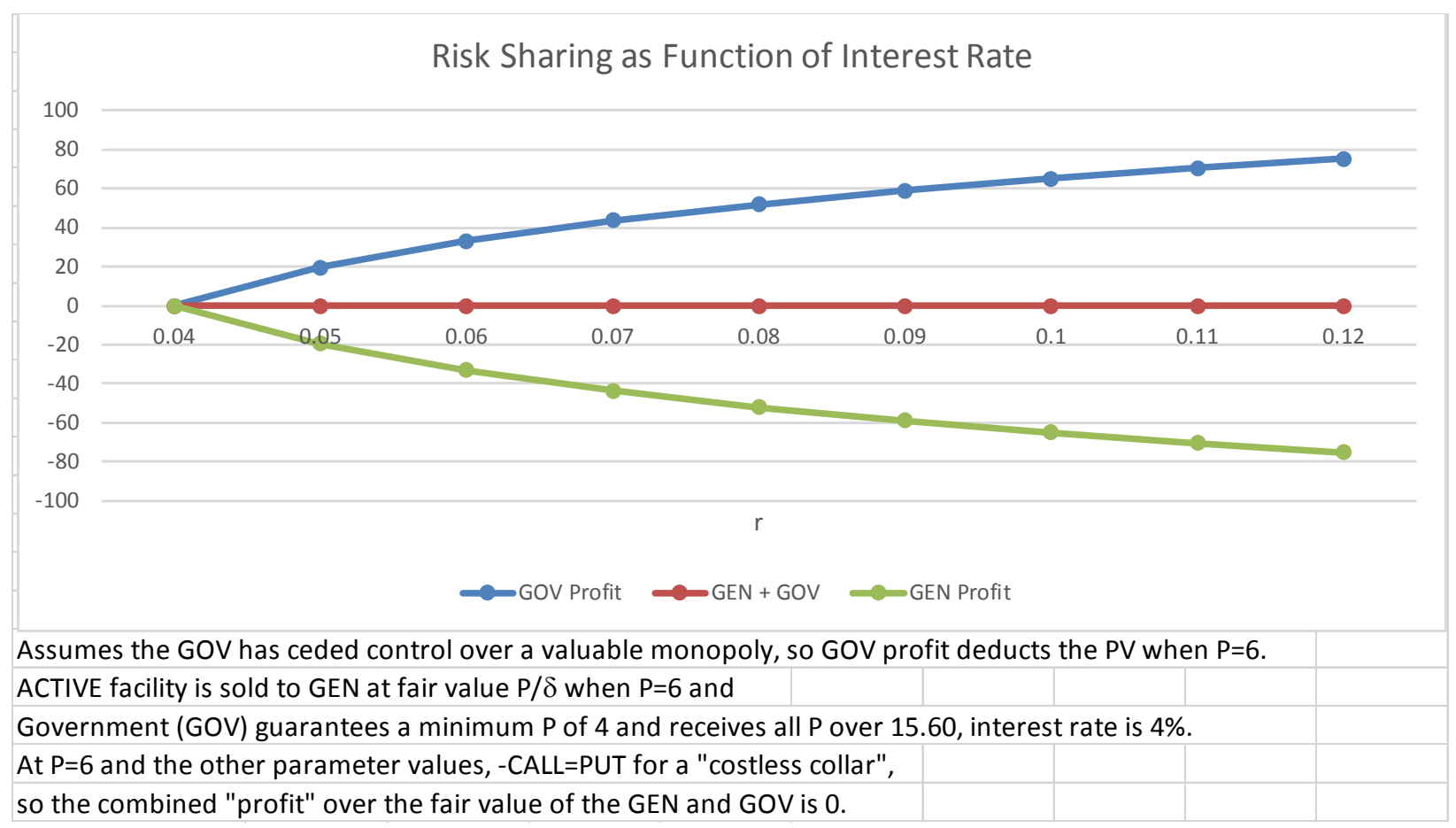

Figure 8

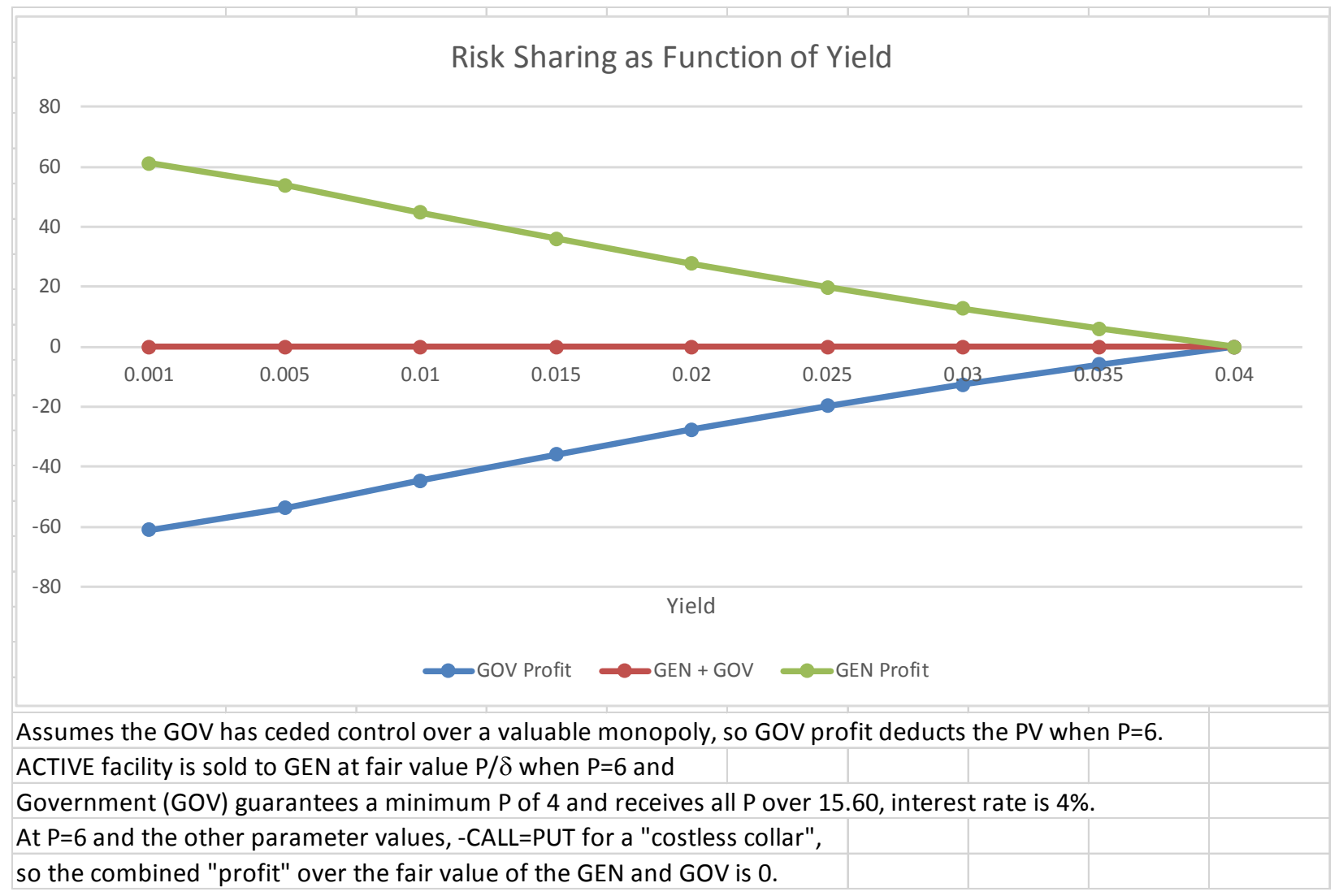


Figure 9

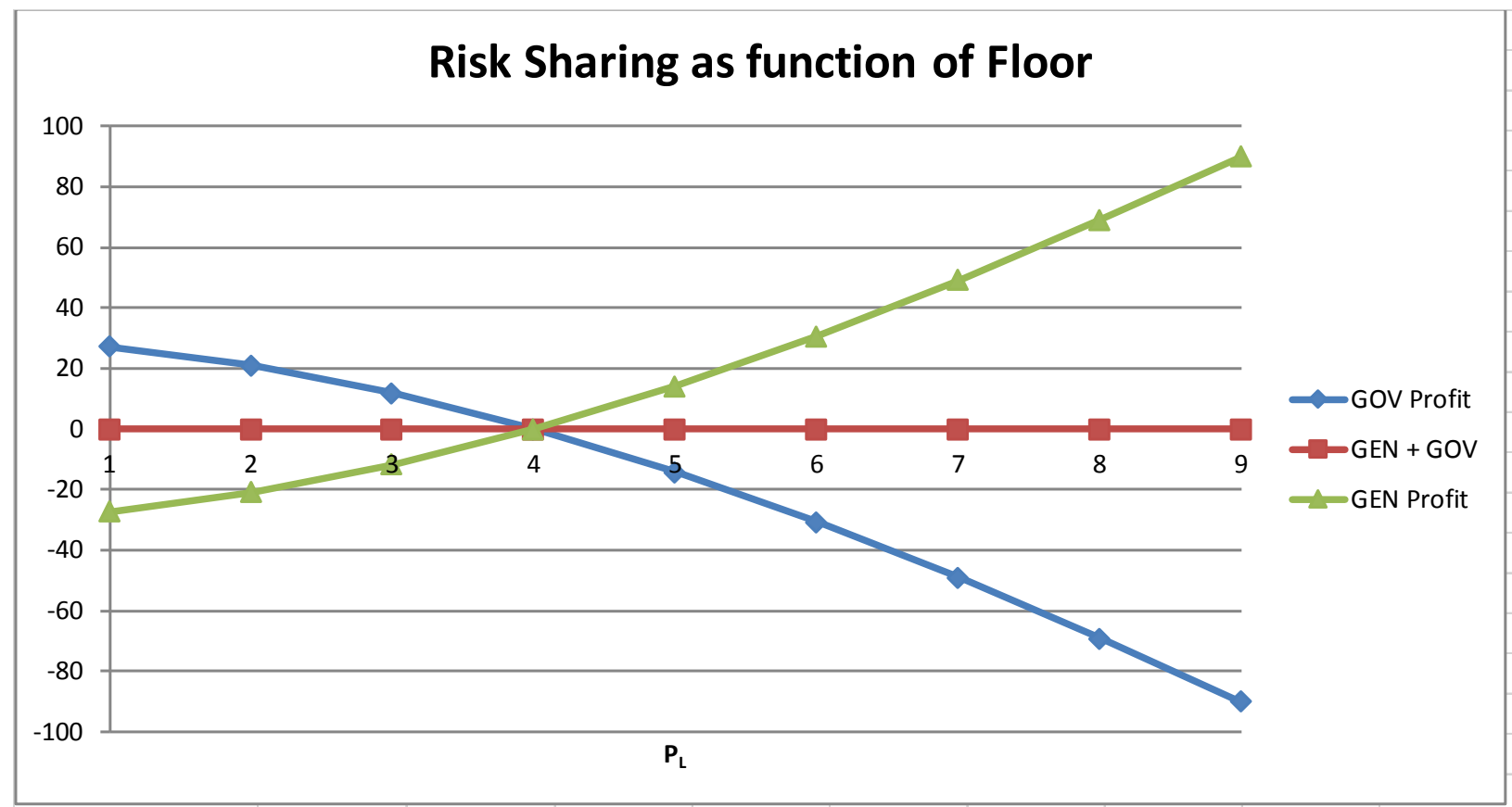

Assumes the GOV has ceded control over a valuable monopoly, so GOV profit deducts the PV when $\mathrm{P}=6$.

ACTIVE facility is sold to GEN at fair value $\mathrm{P} / \delta$ when $\mathrm{P}=6$ and $\delta$ is $4 \%$. Base case is

GOV guarantees a minimum $R$ of 4 and receives all $R$ over 15.60 , interest rate is $4 \%$.

At $\mathrm{P}=6$ and the other parameter values, -CALL=PUT for a "costless collar",

so the combined "profit" over the fair value of the GEN and GOV is 0 .

Figure 10

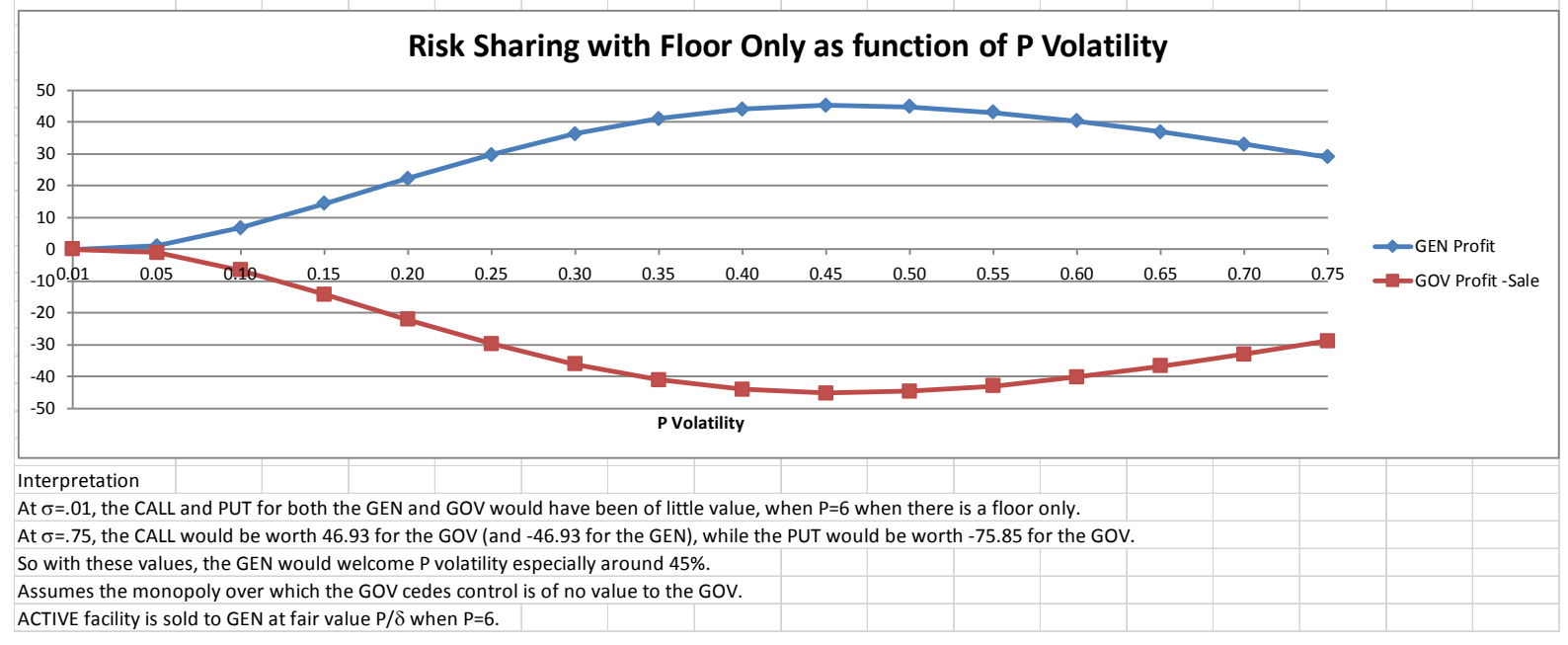


Figure 11

\begin{tabular}{|l|r|r|r|r|r|r|r|r|r|r|}
\hline P & 2 & 4 & 6 & $\mathbf{8}$ & 10 & 12 & 14 & 16 & 18 \\
\hline VC & $\mathbf{4 0 . 2 6}$ & $\mathbf{1 0 1 . 9 1}$ & $\mathbf{1 3 8 . 2 4}$ & $\mathbf{1 7 3 . 0 3}$ & $\mathbf{2 0 5 . 6 8}$ & $\mathbf{2 2 3 . 7 1}$ & $\mathbf{2 4 0 . 3 7}$ & $\mathbf{2 5 6 . 1 2}$ & $\mathbf{2 7 1 . 2 3}$ \\
\hline Regime I & $\mathbf{4 0 . 2 6}$ & 51.90 & 63.14 & 74.03 & 84.60 & 94.85 & 104.81 & 114.49 & 123.89 \\
\hline Regime II & 64.62 & $\mathbf{1 0 1 . 9 1}$ & 139.12 & 178.27 & 219.66 & 263.33 & 309.25 & 357.37 & 407.63 \\
\hline Regime III & 67.24 & 101.91 & $\mathbf{1 3 8 . 2 4}$ & $\mathbf{1 7 3 . 0 3}$ & $\mathbf{2 0 5 . 6 8}$ & 236.08 & 264.20 & 290.08 & 313.77 \\
\hline Regime IV & 6.21 & 88.66 & 135.85 & 172.96 & 205.68 & 236.05 & 265.00 & 293.02 & 320.39 \\
\hline Regime V & 54.72 & 125.33 & 160.35 & 185.20 & 205.63 & $\mathbf{2 2 3 . 7 1}$ & $\mathbf{2 4 0 . 3 7}$ & $\mathbf{2 5 6 . 1 2}$ & $\mathbf{2 7 1 . 2 3}$ \\
\hline
\end{tabular}

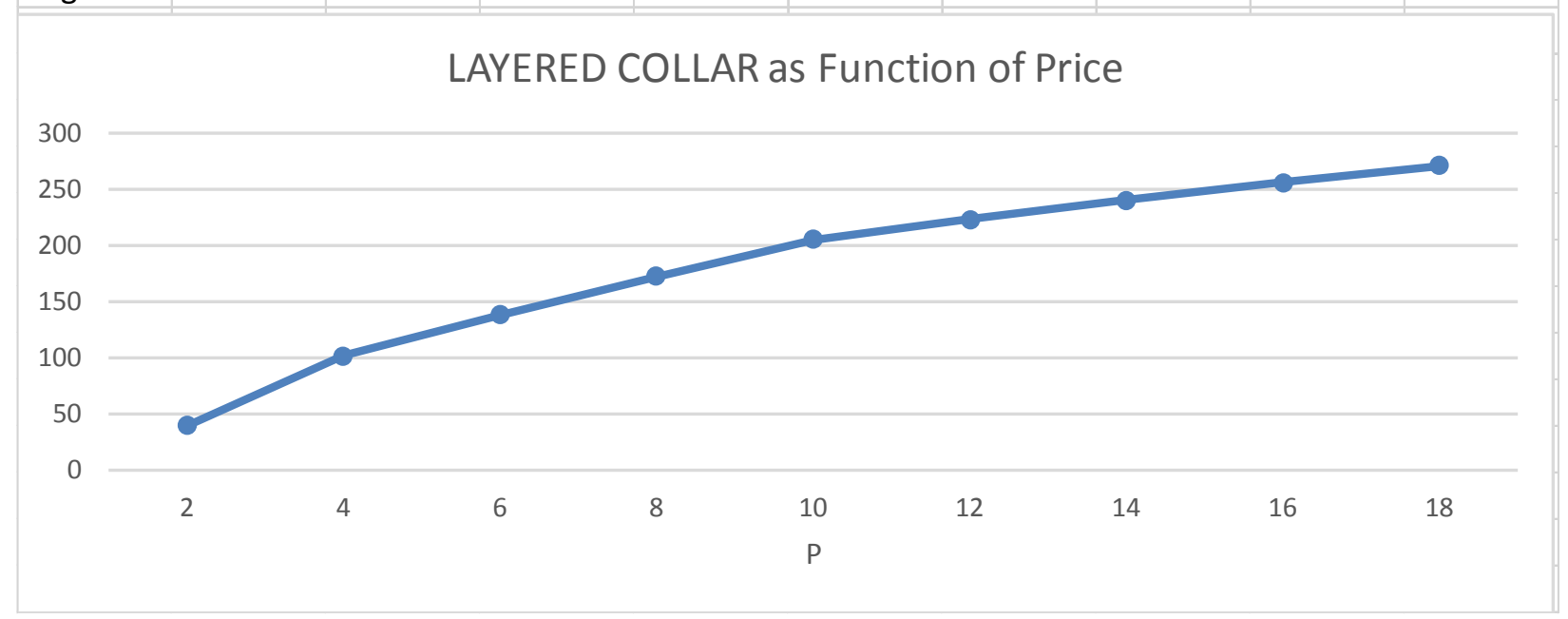

Using Table 2 parameter values, except that floors are 3.5, 4 and ceilings 10, 10.5, risk sharing is .25, .5 on the downside and $.5, .25$ on the upside, calculated from Table 5 and 6 equations. Note that the layered collar values are based on escalating regimes I when $\mathrm{P}=2$, II when $\mathrm{P}=4$, III when $\mathrm{P}=6$ to $10, \mathrm{~V}$ when $\mathrm{P}$ is $12+$.

Figure 12

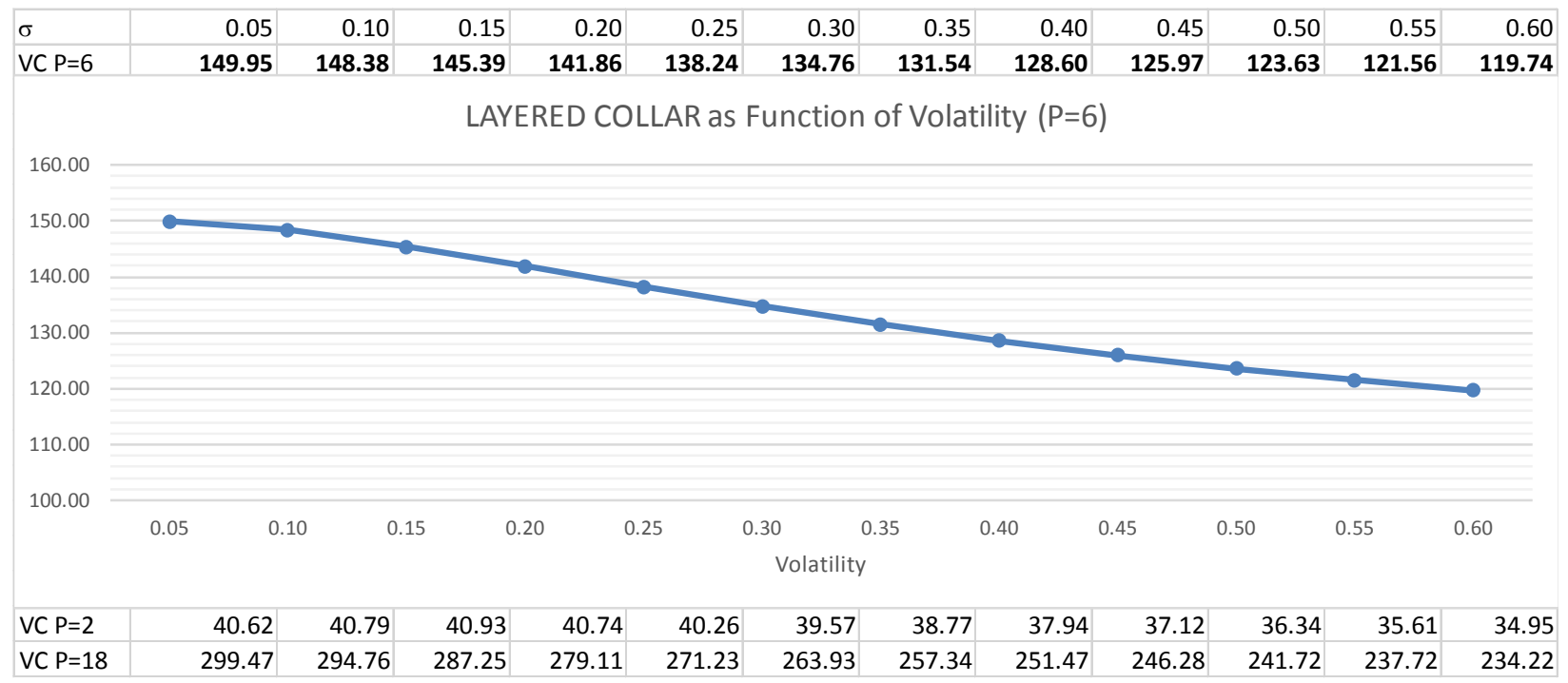


Using Table 2 parameter values, except that floors are 3.5, 4 and ceilings 10, 10.5, risk sharing is .25, .5 on the downside and $.5, .25$ on the upside, calculated from Table 5 and 6 equations. The layered collar values are based on regime III when $P=6$, but regime I when $P=2$, and $V$ when $P=18$ are also shown.

Figure 13

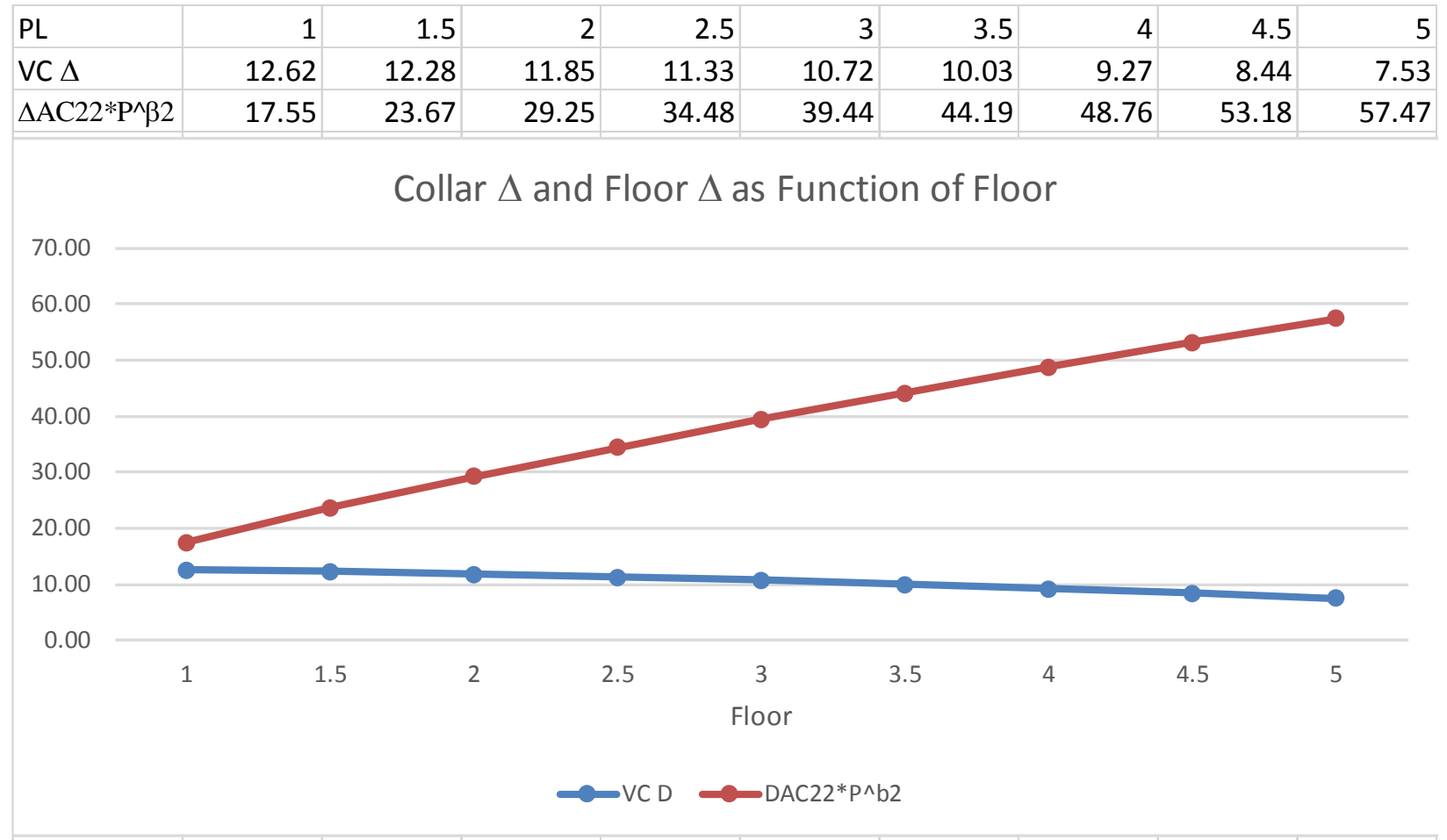

VC $\Delta$ is the middle row of (16), showing that the ACTIVE project with a collar when $P=6$ becomes less sensitive to changes in $\mathrm{P}$ as the floor increases, but the floor $\Delta$ from (17) becomes more important as the floor increases. 
Table 2

Basic Inputs and Outputs for COLLAR ARRANGEMENT

\begin{tabular}{|c|c|c|c|c|}
\hline & A & B & C & D \\
\hline 1 & & & ACTIVE GEN WITH COLLAR & \\
\hline 2 & INPUT & & & EQ \\
\hline 3 & $P$ & 6.00 & & \\
\hline 4 & $\mathrm{~K}$ & 100.00 & & \\
\hline 5 & $\sigma$ & 0.25 & & \\
\hline 6 & $r$ & 0.04 & & \\
\hline 7 & $\delta$ & 0.04 & & \\
\hline 8 & $\mathrm{P}_{\mathrm{L}}$ & 4 & & \\
\hline 9 & $\mathrm{P}_{\mathrm{H}}$ & 10 & & \\
\hline 10 & OUTPUT & & & \\
\hline 11 & VC & 138.3688 & & 6 \\
\hline 12 & VC PV & 150.0000 & $\mathrm{IF}(\mathrm{B} 3<\mathrm{B} 8, \mathrm{~B} 8 / \mathrm{B} 6, \mathrm{IF}(\mathrm{B} 3>\mathrm{B} 9, \mathrm{~B} 9 / \mathrm{B} 6, \mathrm{~B} 3 / \mathrm{B} 7))$ & 6 \\
\hline 13 & $P / \delta$ & 150.0000 & B3/B7 & \\
\hline 14 & $\beta_{1}$ & 1.7369 & $0.5-(B 6-B 7) /\left(B 5^{\wedge} 2\right)+\operatorname{SQRT}\left(\left((B 6-B 7) /\left(B 5^{\wedge} 2\right)-0.5\right)^{\wedge} 2+2^{*} B 6 /\left(B 5^{\wedge} 2\right)\right)$ & 4 \\
\hline 15 & $\beta 2$ & -0.7369 & $0.5-(B 6-B 7) /\left(B 5^{\wedge} 2\right)-S Q R T\left(\left((B 6-B 7) /\left(B 5^{\wedge} 2\right)-0.5\right)^{\wedge} 2+2^{*} B 6 /\left(B 5^{\wedge} 2\right)\right)$ & 4 \\
\hline 16 & $\mathrm{AC} 11 * \mathrm{P} \wedge \beta 1$ & 40.1361 & B21*(B3^B14) & \\
\hline 17 & $\mathrm{AC} 21 * \mathrm{P} \wedge \beta 1$ & -41.6129 & $\mathrm{~B} 22^{*}\left(\mathrm{~B} 3^{\wedge} \mathrm{B} 14\right)$ & \\
\hline 18 & $\mathrm{AC} 22 * \mathrm{P} \wedge \beta 2$ & 29.9818 & B23*(B3^B15) & \\
\hline 19 & $\mathrm{AC} 32 * \mathrm{P} \wedge \beta 2$ & -117.2670 & $B 24^{*}\left(B 3^{\wedge} B 15\right)$ & \\
\hline 20 & Vc & 138.3688 & $\mathrm{~B} 12+\mathrm{B} 17+\mathrm{B} 18$ & \\
\hline 21 & AC11 & 1.7862 & $\left(\mathrm{~B} 9 /\left(\mathrm{B} 9^{\wedge} \mathrm{B} 14\right)-\mathrm{B} 8 /\left(\mathrm{B} 8^{\wedge} \mathrm{B} 14\right)\right) *(\mathrm{~B} 25 / \mathrm{B} 27)$ & 11 \\
\hline 22 & AC21 & -1.8520 & $(\mathrm{~B} 9 /(\mathrm{B} 9 \wedge \mathrm{B} 14))^{*}(\mathrm{~B} 25 / \mathrm{B} 27)$ & 11 \\
\hline 23 & AC22 & 112.2797 & $\left(-\mathrm{B} 8 /\left(\mathrm{B} 88^{\wedge} \mathrm{B} 15\right)\right) *(\mathrm{~B} 26 / \mathrm{B} 27)$ & 11 \\
\hline 24 & AC32 & -439.16 & $\left(\mathrm{~B} 9 /\left(\mathrm{B} 9^{\wedge} \mathrm{B} 15\right)-\mathrm{B} 8 /\left(\mathrm{B} 8^{\wedge} \mathrm{B} 15\right)\right) *(\mathrm{~B} 26 / \mathrm{B} 27)$ & 11 \\
\hline 25 & {$[\quad]$} & -0.0400 & $(B 6 * B 15-B 6-B 7 * B 15)$ & 11 \\
\hline 26 & $(\quad)$ & -0.0400 & $(\mathrm{~B} 6 * \mathrm{~B} 14-\mathrm{B} 6-\mathrm{B} 7 * \mathrm{~B} 14)$ & 11 \\
\hline 27 & \{\} & 0.0040 & $(\mathrm{~B} 14-\mathrm{B} 15) * \mathrm{~B} 6 * \mathrm{~B} 7$ & 11 \\
\hline 28 & Ve & $\mathrm{IF}(\mathrm{B} 3<\mathrm{B} 8, \mathrm{~B}$ & $\left.\mathrm{B} 8 / \mathrm{B} 6+\mathrm{B} 21^{*}\left(\mathrm{~B} 3^{\wedge} \mathrm{B} 14\right), \mathrm{IF}\left(\mathrm{B} 3>\mathrm{B} 9, \mathrm{~B} 9 / \mathrm{B} 6+\mathrm{B} 24^{*}\left(\mathrm{~B} 3^{\wedge} \mathrm{B} 15\right), \mathrm{B} 3 / \mathrm{B} 7+\mathrm{B} 22^{*}\left(\mathrm{~B} 3^{\wedge} \mathrm{B} 14\right)+\mathrm{B} 23^{*}\left(\mathrm{~B} 3^{\wedge} \mathrm{B} 15\right)\right)\right)$ & \\
\hline 29 & ODE & 0.0000 & $0.5^{*}(\mathrm{~B} 5 \wedge 2) *(\mathrm{~B} 3 \wedge 2) * \mathrm{~B} 31+(\mathrm{B} 6-\mathrm{B} 7) * \mathrm{~B} 3 * \mathrm{~B} 30-\mathrm{B} 6 * \mathrm{~B} 11+\mathrm{MIN}(\mathrm{MAX}(\mathrm{B} 8, \mathrm{~B} 3), \mathrm{B} 9)$ & 5 \\
\hline 30 & VC $\Delta$ & 9.2711 & IF $\left(B 3<B 8, B 14^{*} B 21^{*}\left(B 3^{\wedge}(B 14-1)\right), I F\left(B 3>B 9, B 15^{*} B 24^{*}\left(B 3^{\wedge}(B 15-1)\right), 1 / B 7+B 14^{*}{ }^{*} B 2^{*}\left(B 3^{\wedge}(B 14-1)\right)+B 15^{*} B 23^{*}\left(B 3^{\wedge}(B 15-1)\right)\right)\right)$ & 16 \\
\hline 31 & $\operatorname{Ve} \Gamma$ & -0.4136 & 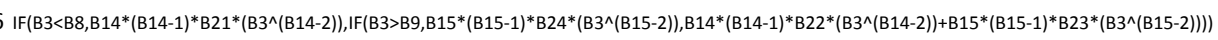 & \\
\hline 32 & Floor Deltas & & & \\
\hline 33 & $\triangle \mathrm{AC} 11 * \mathrm{P} \wedge \beta 1$ & -0.6703 & $-\left((1-B 14)^{*}\left(\mathrm{~B} 8^{\wedge}(-\mathrm{B} 14)\right)^{*}(\mathrm{~B} 25 / \mathrm{B} 27)\right)$ & 17 \\
\hline 34 & $\triangle \mathrm{AC} 22 * \mathrm{P} \wedge \beta 2$ & 48.7556 & $-(1-\mathrm{B} 15)^{*} \mathrm{~B} 8^{\wedge}(-\mathrm{B} 15)^{*}(\mathrm{~B} 26 / \mathrm{B} 27)$ & 17 \\
\hline 35 & $\triangle \mathrm{AC} 32 * \mathrm{P} \wedge \beta 2$ & 48.7556 & $-(1-\mathrm{B} 15)^{*} \mathrm{~B} 8^{\wedge}(-\mathrm{B} 15)^{*}(\mathrm{~B} 26 / \mathrm{B} 27)$ & 17 \\
\hline 36 & Ceiling Deltas & & & \\
\hline 37 & $\Delta \mathrm{AC} 11 * \mathrm{P} \wedge \beta 1$ & 0.1365 & $(1-B 14) *$ B9^$(-B 14) *(B 25 / B 27)$ & 18 \\
\hline 38 & $\Delta \mathrm{AC} 21 * \mathrm{P} \wedge \beta 1$ & 0.1365 & $(1-B 14)^{*}\left(B 9^{\wedge}(-B 14) *(B 25 / B 27)\right)$ & 18 \\
\hline 39 & $\triangle \mathrm{AC} 32 * \mathrm{P} \wedge \beta 2$ & -95.7809 & $(1-\mathrm{B} 15) *\left(\mathrm{~B} 9^{\wedge}(-\mathrm{B} 15) *(\mathrm{~B} 26 / \mathrm{B} 27)\right)$ & 18 \\
\hline
\end{tabular}

The COLLAR VC is from (6), power parameters from (4), the option coefficients from (11), the collar delta from (16), the floor deltas from (17) and the ceiling deltas from (18). 
Table 3

Switch Option Coefficients for the With-Collar Model for Variations in Floor and Cap Levels

\begin{tabular}{|c|c|c|c|c|c|c|c|c|c|c|}
\hline \multicolumn{1}{|c|}{} & \multicolumn{5}{|c|}{ Panel A: $\mathrm{A}_{C 11}$} & \multicolumn{5}{|c|}{ Panel $\mathrm{B}: \mathrm{A}_{C 21}$} \\
\hline $\mathrm{P}_{\mathrm{H}}$ & $\mathrm{P}_{\mathrm{L}}=0$ & $\mathrm{P}_{\mathrm{L}}=1$ & $\mathrm{P}_{\mathrm{L}}=2$ & $\mathrm{P}_{\mathrm{L}}=3$ & $\mathrm{P}_{\mathrm{L}}=4$ & $\mathrm{P}_{\mathrm{L}}=0$ & $\mathrm{P}_{\mathrm{L}}=1$ & $\mathrm{P}_{\mathrm{L}}=2$ & $\mathrm{P}_{\mathrm{L}}=3$ & $\mathrm{P}_{\mathrm{L}}=4$ \\
\hline 10 & 0.0000 & 8.2537 & 4.2116 & 2.6454 & 1.7862 & -1.8520 & -1.8520 & -1.8520 & -1.8520 & -1.8520 \\
\hline 20 & 0.0000 & 8.9944 & 4.9523 & 3.3862 & 2.5270 & -1.1112 & -1.1112 & -1.1112 & -1.1112 & -1.1112 \\
\hline 50 & 0.0000 & 9.5400 & 5.4979 & 3.9317 & 3.0726 & -0.5656 & -0.5656 & -0.5656 & -0.5656 & -0.5656 \\
\hline 100 & 0.0000 & 9.7663 & 5.7241 & 4.1580 & 3.2988 & -0.3394 & -0.3394 & -0.3394 & -0.3394 & -0.3394 \\
\hline 200 & 0.0000 & 9.9020 & 5.8599 & 4.2937 & 3.4346 & -0.2036 & -0.2036 & -0.2036 & -0.2036 & -0.2036 \\
\hline 500 & 0.0000 & 10.0020 & 5.9599 & 4.3937 & 3.5345 & -0.1037 & -0.1037 & -0.1037 & -0.1037 & -0.1037 \\
\hline 1000 & 0.0000 & 10.0435 & 6.0013 & 4.4352 & 3.5760 & -0.0622 & -0.0622 & -0.0622 & -0.0622 & -0.0622 \\
\hline Infinity & 0.0000 & 10.1057 & 6.0635 & 4.4974 & 3.6382 & 0.0000 & 0.0000 & 0.0000 & 0.0000 & 0.0000 \\
\hline & & & & & & & & & & \\
\hline & & & & & & & & $P a n e l$ & $\mathrm{D}: \mathrm{A}_{C 32}$ & \\
\hline $\mathrm{P}_{\mathrm{H}}$ & $\mathrm{P}_{\mathrm{L}}=0$ & $\mathrm{P}_{\mathrm{L}}=1$ & $\mathrm{P}_{\mathrm{L}}=2$ & $\mathrm{P}_{\mathrm{L}}=3$ & $\mathrm{P}_{\mathrm{L}}=4$ & $\mathrm{P}_{\mathrm{L}}=0$ & $\mathrm{P}_{\mathrm{L}}=1$ & $\mathrm{P}_{\mathrm{L}}=2$ & $\mathrm{P}_{\mathrm{L}}=3$ & $\mathrm{P}_{\mathrm{L}}=4$ \\
\hline 10 & 0.000 & 10.106 & 33.685 & 68.123 & 112.280 & -551 & -541 & -518 & -483 & -439 \\
\hline 20 & 0.000 & 10.106 & 33.685 & 68.123 & 112.280 & -1838 & -1828 & -1804 & -1770 & -1726 \\
\hline 50 & 0.000 & 10.106 & 33.685 & 68.123 & 112.280 & -9027 & -9017 & -8994 & -8959 & -8915 \\
\hline 100 & 0.000 & 10.106 & 33.685 & 68.123 & 112.280 & -30090 & -30080 & -30057 & -30022 & -29978 \\
\hline 200 & 0.000 & 10.106 & 33.685 & 68.123 & 112.280 & -100299 & -100289 & -100265 & -100231 & -100187 \\
\hline 500 & 0.000 & 10.106 & 33.685 & 68.123 & 112.280 & -492596 & -492586 & -492562 & -492528 & -492484 \\
\hline 1000 & 0.000 & 10.106 & 33.685 & 68.123 & 112.280 & -1641948 & -1641938 & -1641914 & -1641880 & -1641836 \\
\hline Infinity & 0.000 & 10.106 & 33.685 & 68.123 & 112.280 & Infinity & Infinity & Infinity & Infinity & Infinity \\
\hline
\end{tabular}

Using the baseline data, the coefficients $A_{C 11}, A_{C 21}, A_{C 22}, A_{C 32}$ are evaluated from (11) for the various indicated $P_{L}$ and $P_{H}$ values. 


\section{Table 4}

Costless Collars

\begin{tabular}{|l|r|r|r|r|r|r|r|r|r|r|}
\hline $\mathrm{P}_{\mathrm{L}}$ & 1 & 1.5 & 2 & 2.5 & 3 & 3.5 & 4 & 4.5 & 5 \\
\hline $\mathrm{P}_{\mathrm{H}}$ & 409.48 & 157.47 & 79.93 & 47.24 & 30.74 & 21.37 & 15.60 & 11.82 & 9.22 \\
\hline AC21 $* \mathrm{P}^{\beta 1}$ & -2.70 & -5.46 & -8.99 & -13.25 & -18.19 & -23.78 & -29.98 & -36.79 & -44.18 \\
\hline $\mathrm{AC} 22 * \mathrm{P}^{\beta 2}$ & 2.70 & 5.46 & 8.99 & 13.25 & 18.19 & 23.78 & 29.98 & 36.79 & 44.18 \\
\hline
\end{tabular}

Based on Table 2 base parameter values except for changing $\mathrm{P}_{\mathrm{L}}$, the $\mathrm{P}_{\mathrm{H}}$ is calculated as that ceiling which results in the negative written call equal to the held put for Regime II, when P is between $\mathrm{P}_{\mathrm{L}}$ and $\mathrm{P}_{\mathrm{H}}$. 